
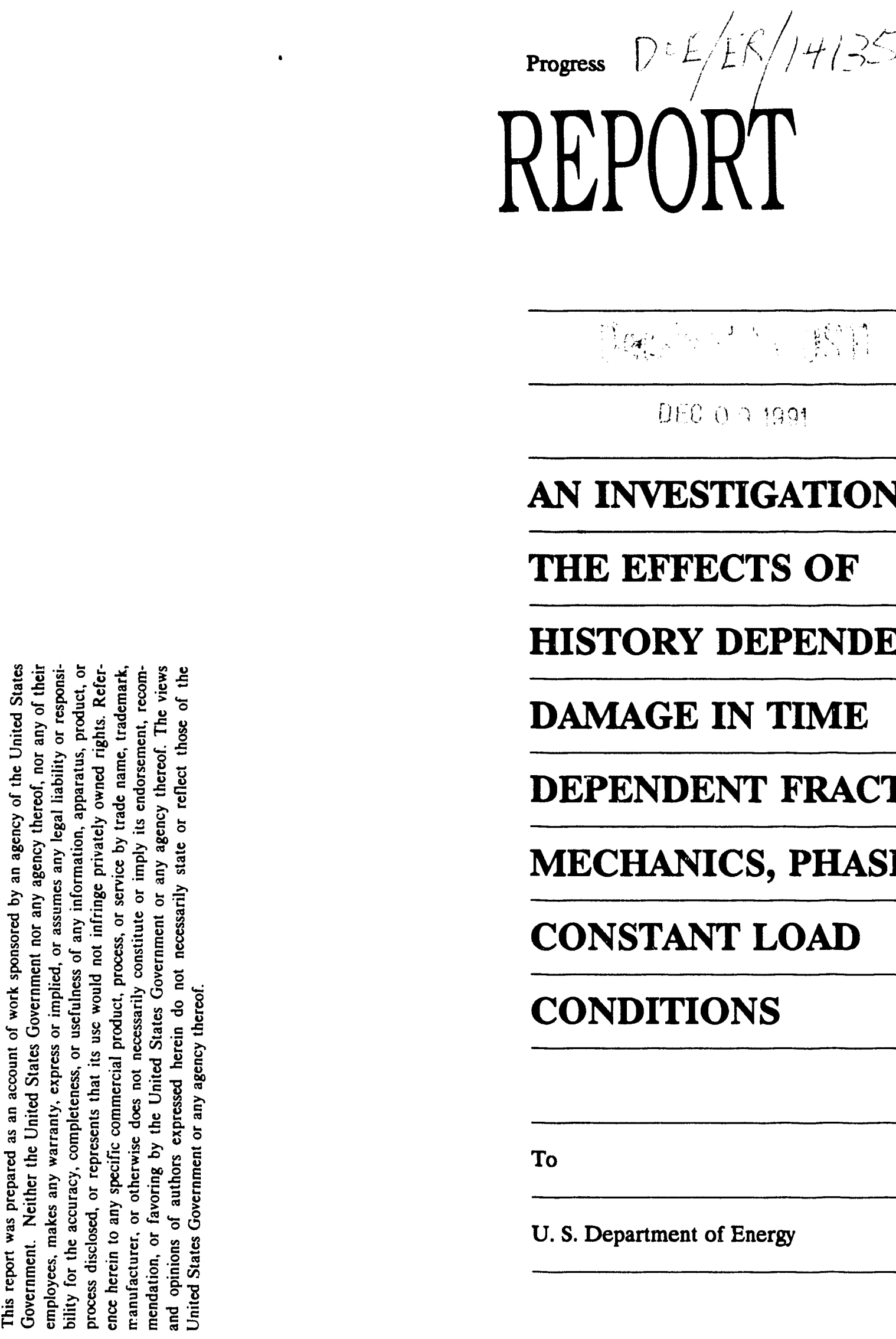

\title{
AN INVESTIGATION OF
}

THE EFFECTS OF

HISTORY DEPENDENT

DAMAGE IN TIME

DEPENDENT FRACTURE

MECHANICS, PHASE I,

CONSTANT LOAD

\section{CONDITIONS}

To

U. S. Department of Energy

November 14, 1991 


\title{
PROGRESS REPORT
}

\section{AN INVESTIGATION OF THE EFFECTS OF HISTORY DEPENDENT DAMAGE IN TIME DEPENDENT FRACTURE MECHANICS, PHASE I, CONSTANT LOAD CONDITIONS}

by

DOE/ER/14135--T1

DE92 004428

\author{
F. W. Brust, P. Krishriaswamy, and N. D. Ghadiali \\ Battelle \\ 505 King Avenue \\ Columbus, $\mathrm{OH} 43201$
}

Grant No. DE-FG02-90ER14135

\section{INTRODUCTION}

The demands for structural systerns to perform reliably under severe operating conditions continue to increase. Structural components such as hot-reheat steam lines, heaters, drums, and primary steam lines in a modern power plant experience degradation and damage because they must operate in a high-temperature environment where time dependent straining becomes important. In addition, reusable space vehicles must be capable of withstanding repeated thermomechanical histories without failure. This work is focused on studying creep crack growth, a frequent failure mechanism of structural componenis which experience time dependent straining.

Most investigations which have appeared to date are colicerned with crcep crack growth which occurs under a constant load and temperature. However, most structural components experience complicated load histories. For example, each time a power plant is shut down for maintenance purposes, a number of components experience low cycle fatigue. The history of degradation and damage which accumulates at the crack tip is greatly influenced by these transients. The subject of this work is a study of history effects on the creep crack growth process.

The development of a successful predictive analytical methodology involves i) the choice of an appropriate constitutive model that incorporates both nonlinear material behavior and load history effects and ii) selection of a suitable fracture parameter that characterizes the crack tip process under constant and variable loads. This work focuses 
primarily on implementing nonlinear material models that have described load history effects successfully into a finite element (FE) program and on studying the constant load creep crack growth problem. Once such a tool that models the material accurately is available in a numerically robust form, the parameters that govern the creep crack growth process can be studied in great detail. Development of such an algorithm is therefore an essential part of this work. As shown by Saxena [1], the constitutive model chosen significantly influences the stress and strain fields in the vicinity of the crack tip in a time dependent material.

In the following section a brief review of constitutive models is presented along with the implications of using them in creep crack growth studies under variable loads. The model selected for this study, developed by Murakami and Ohno [2], is discussed along with its special features that make is particularly suitable for this investigation. This model is based on the creep hardening surface and is particularly useful for variable and fully reversed load histories. In Section 3 an implicit finite element algorithm for this model is derived. Details regarding implementation of this method into FVP [3], an existing FE program to study creep crack growth, are also discussed. The results of the algorithm are verified against closed form solutions for simple geometries in Section 4. Sources of error and differences between using explicit and implicit schemes are also presented. Section 5 compares the numerical results with experimental data [2] for the case of combined tension and torsion and fully reversed load histories. Section 6 provides results of some of the constant load creep crack growth analyses that have been performed to date.

Because a wealth of experimental data has been developed for creep crack under constant load conditions, the need to develop our own creep crack growth data for this study was minimal. In particular, the VAMAS report (Reference [4]) provides state-of-the-art constant load creep crack growth data produced in many countries. Professor A. Saxena of Georgia Tech, who is one of the main participants of the VAMAS project, has been extremely helpful in providing us with additional data. These experiments are being modeled via the finite element method, and fracture theories are currently being developed and examined. Conclusions of the Phase I work as well as work planned for the future are discussed in Section 7. Finally, Sections 8 and 9 discuss publications and the Phase II effort, respectively.

Finally, the implementation of large strain and friction/contact algorithms into the finite element code and the implementation of three additional non-linear constitutive laws (endochronic law [5], Bodner [6] (popular at the Air Force), and the Walker Model [6] (popular at NASA) are not discussed here. The large strain algorithm is complete, the 
endochronic theory is nearly complete, while subroutines for the Bodner and Walker models were obtained from the agencies described above. These theories will be used during the Phase II effort as we sidy load history dependent crack growth in conjunction with the Murakami-Ohno law. The friction/contact capability is necessary during Phase II since, during global unloading, the crack faces will come into contact under certain load conditions to be considered.

\section{CONSTITUTIVE MODELLING}

Time dependent behavior under constant sustained load at high temperature is generally classified into three phases: primary or trarsient creep, secondary, and tertiary creep as shown in Figure 1a. For a cracked component, in the vicinity of the growing crack tip, the material is in a state of nonlinear transient creep. Hence, traditional creep equations [4], such as the Norton law for secondary creep, are not applicable in this region. Therefore, all further discussion in this work will pertain to models that describe primary or transient creep.

Figure $1 \mathrm{~b}$ shows a schematic of a typical creep strain response under a constant sustained load applied to a uniaxial specimen for time $t_{1}$. At time $t_{1}$ if the load is removed then a material may exhibit "anelastic" recovery in the absence of any applied load. If however the load is fully reversed with the same magnitude, a temporary increase in strain rate is observed due to stress softening $[2,7]$ before the creep rate asymptotically approaches that without stress reversals. Models that are capable of describing such phenomena are therefore important in studying creep crack growth under variable loads. Conventional Time-Hardening or Strain-Hardening models [4] which successfully describe creep under constant sustained load cannot account for these phenomena that occur under varying loads.

Although a number of constitutive equations have been proposed to handle such phenomena [6], their mathematical structures are often too complicated to be employed in practical analyses of creep. The determination of material constants in these models also causes major difficulties. One moidel that successfully describes creep under non-steady state of stress and which is simple to obtain material constants is that developed by Murakami and Ohno [2] and is based on the concept of a creep hardening surface (CHS).

This model has been shown to perform very well when compared to complex load experimental data [8]. Moreover, in the Inoue benchmark problem [8], the Murakami and Ohno model performs as well or better than the ten other constitutive laws studied in that 
work. In this model a boundary $g=0$ with a center $\alpha_{i j}$ and radius $\rho$, analogous to the concept of a yield surface in the theory of plasticity [8], is first defined. On the boundary $(g=0)$ the creep deformation pertains to irreversible deformations whereas within the boundary $(\mathrm{g}<0)$ the creep rate temporarily increases cue to stress softening.

The total strain tensor, $\epsilon_{\mathrm{ij}}$ as described by the model is first separated into a time-independent elastic component $\epsilon_{\mathrm{ij}}{ }^{\mathrm{e}}$ and a time-dependent creep component $\epsilon_{\mathrm{ij}}{ }^{\mathrm{c}}$ given by

$$
\epsilon_{i j}=\epsilon_{i j}^{c}+\epsilon_{i j}^{c}
$$

In standard indical notation, $\sigma_{\mathrm{ij}}$ and $\mathrm{s}_{\mathrm{ij}}$ are used to denote the total and deviatoric component of the stress tensor, respectively. For the general multi-axial case, the creep strain rate in this model is given by

$$
\dot{\epsilon}_{i j}^{c}=C(\bar{\sigma}, q) s_{i j}=\frac{3}{2} m(A)^{\frac{1}{m}}(\bar{\sigma})^{\frac{n-m}{m}}(q)^{\frac{m-1}{m}} s_{i j}
$$

where A, m, and n are material constants,

and

$$
\begin{gathered}
\bar{\sigma}=\left(\frac{3}{2} s_{\mathrm{ij}} s_{\mathrm{ij}}\right)^{\frac{1}{2}} \\
q=\rho+\left(\frac{\epsilon^{c_{\mathrm{j}}}-\alpha_{\mathrm{ij}}}{\bar{\sigma}}\right) s_{\mathrm{ij}} .
\end{gathered}
$$

The evolution equations for the center of the yield surface $\alpha_{\mathrm{ij}}$, and radius $\rho$ are given by

$$
\begin{gathered}
\dot{\alpha}_{i j}=\dot{\rho}=0 \text { if } g<0 \text { or } \frac{\partial g}{\partial \epsilon_{i j}^{c}} \dot{\epsilon}_{i j}^{c} \leq 0 \\
\dot{\alpha}_{i j}=\frac{1}{2}\left(\dot{\epsilon}_{\mathbf{l d}}^{c} \eta_{l d}\right) \eta_{i j} \quad \dot{\rho}=\frac{1}{\sqrt{6}} \dot{\epsilon}_{i j}^{c} \eta_{i j} \quad \text { if } g=0 \text { and } \frac{\partial g}{\partial \epsilon_{i j}^{c}} \dot{\epsilon}_{i j}^{c}>0
\end{gathered}
$$

where $\eta_{i j}$ is the outward normal vector to the CFiS defined as 


$$
\eta_{i j}=\frac{5}{\left\{\left(\epsilon_{k d}^{c}-\alpha_{i d}\right)\left(\epsilon_{k j}^{c}-\alpha_{k j}^{c}\right)\right\}^{\frac{1}{2}}} .
$$

The CHS is given as

$$
\begin{aligned}
g=\frac{2}{3}\left(\epsilon_{i j}^{c}-\alpha_{i j}\right)\left(\epsilon_{i j}^{c}-\alpha_{i j}\right)-\rho^{2}= & 0 \text { on CHS } \\
& <0 \text { inside }
\end{aligned}
$$

The radius and center of the $\mathrm{CHS}$ therefore change only when the material state is on the CHS $(g=0)$ and remain the same when the state of creep strain is inside the CHS $(g<0)$.

In addition to describing stress reversal situations accurately, the principal advantage of this theory is that it coincides with the classical strain hardening theory for the case of uniaxial constant stress. Therefore, all material constants for this theory can be obtained from uniaxial creep data which exist for a most materials. This is a tremendous advantage in this model compared to the other models (see References [6] and [8]).

The above equations are used in describing the Simple Theory [2]. The authors [2] also propose a more Elaborate Theory to account for non-coaxiality between the creep rate tensor $\dot{\epsilon}_{i j}^{c}$ and the deviatoric stress rate tensor $s_{i j}$ whenever necessary. For this theory the creep strain rate, $\epsilon_{i j}^{c}$, is given by

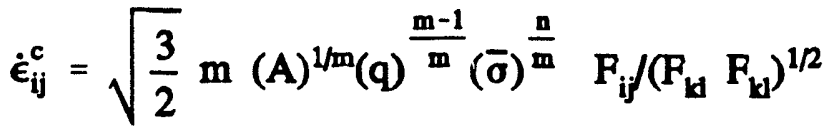

$$
\begin{aligned}
& F_{i j}=\frac{3}{2} \rho \frac{s_{i j}}{\bar{\sigma}}-\xi\left\{1-\frac{q}{2 p}\right\}\left\{\epsilon_{i j}^{c}-\alpha_{i j}\right\}
\end{aligned}
$$

and

$$
q=2 p\left\{\frac{1}{2}+\left(\epsilon_{i j}^{c}-\alpha_{i j}\right) \frac{s_{i j}}{2 p \bar{\sigma}}\right\}^{\zeta}
$$

In a second paper Ohno, Murakami, and Ueno [5] extend their earlier work [2] 
to account for the anelastic recovery upon unloading. For this theory the total creep strain is separated into viscous (non-recoverable) and anelastic (recoverable) components given by

$$
\epsilon_{i j}^{c}=\epsilon_{i j}^{v}+\epsilon_{i j}^{a}
$$

The anelastic component of the creep strain rate is described by

$$
\dot{\epsilon}_{i j}^{a}=A_{1}\left\{\frac{3}{2} A_{2} s_{i j}-\epsilon_{i j}^{a}\right\}
$$

where $A_{1}$ and $A_{2}$ are material constants determined from creep/creep-recovery tests. The viscous component of the creep strain, $\epsilon_{i j}^{v}$, is described by Equations (2)-(7) given above for the Simple Theory.

A finite element (FE) algorithm using an implicit or tangent modulus scheme will be derived next for the case of the simple theory of Ohno and Murakami [2]. The implicit algorithm has the advantage of ensuring convergent and stable solution for large time step sizes, unlike explicit integration schemes. In studying creep crack growth phenomena the implicit scheme will therefore allow us to investigate the nature of the crack tip fields over long times efficiently and accurately and also the variation of fracture parameters [9] with time. References $[8,10,11-12,14]$ compare the performance of more than ten different creep constitutive theories, clearly shows that the Murakami-Ohno constitutive laws can model the behavior of complex multi-axial loads cases.

\section{THE IMPLICIT FE ALGORITHM}

In an implicit scheme involving finite increments in time $\Delta t$, the problem involves finding a solution at time $\mathrm{t}^{\mathrm{n}+1}$, given a solution at time $\mathrm{t}^{\mathrm{n}}$ where the superscript $\mathrm{n}$ indicates the time step. The solution at all times must satisfy the usual equations of static equilibrium in the absence of body forces, the kinematic relation between strains and displacements, and the given constitutive model.

The algorithm presented here to study high temperature creep of materials is developed along the same lines as those outlined by Owen and Hinton [13] available in the FE code FVP [3]. For a given time step $\Delta t$, the change in the stress $\Delta \boldsymbol{g}$, change in total strain $\Delta €$, and creep strain $\Delta \boldsymbol{\epsilon}^{\mathrm{c}}$ are related by the equation 


$$
\Delta \sigma=D\left(\Delta \underline{\epsilon}-\Delta \underline{\epsilon}^{9}\right)
$$

where $\underline{\mathrm{D}}$ is the matrix of elastic constants for the material. Once $\Delta_{\underline{\epsilon}}{ }^{\mathrm{c}}$ is known, this Equation (13) can be restated for the creep constitutive model described above as

$$
\Delta \boldsymbol{\sigma}=\hat{\mathbf{D}}(\Delta \epsilon-\mathbf{E} \Delta \mathbf{t})
$$

In Equation (14) $\hat{D}$ is used to define the stiffness matrix $K$ and $\underline{E}$ is used to modify the change in the force vector $\Delta \mathrm{E}$ in the global equation that relates the change in forces, $\Delta \mathrm{F}$, and displacements, $\Delta$ during the time step $\Delta t$, or

$$
\Delta \mathbf{u}=\mathbf{K}^{-1} \Delta \mathrm{F}
$$

The matrices $\hat{\mathrm{D}}$ and $\underline{\mathrm{E}}$ will differ for the two cases $\mathrm{i}$ ) when the state of strain is on the CHS, that is, $\mathrm{g}=0$, and ii) when the state of strain is inside the CHS $\mathrm{g}<0$. The two algorithms are therefore derived separately.

The change in the creep strain vector in Equation (13) for time $\Delta t$ for the implicit scheme is given as

$$
\Delta \underline{\epsilon}^{c}=\left[(1-\theta) \dot{\epsilon}^{c "}+\theta \dot{\dot{\epsilon}}^{c^{n+1}}\right] \Delta t
$$

where $0.5<\theta<1$ is a parameter for the forward difference method used in the implicit method to ensure a stable convergent solution [10]. If $\theta=0$, the method reduces to an explicit integration scheme [13]. The creep strain rate $\boldsymbol{\xi}^{n+1}$ in Equation (16) can be obtained from Equation (2) as

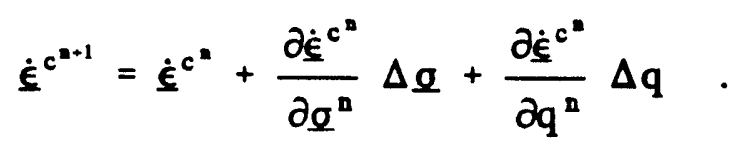

For convenience, we define 


$$
\underline{H}_{0}{ }^{n}=\frac{\partial \dot{\underline{\epsilon}}^{c^{*}}}{\partial \underline{\underline{g}}}
$$

and

$$
\underline{G}_{0}^{n}=\frac{\partial \dot{\varepsilon}^{c^{n}}}{\partial q^{n}}
$$

Once $\Delta q$ is established in terms of quantities known at time $t^{\mathrm{n}}$, Equations (14), (16) and (17) can be used to solve for $\Delta \sigma$ and, hence, obtain the matrices $\mathcal{E}$ and $\underline{E}$ for the two cases.

Case i) State of Strain on the CHS, $g=0$

On the CHS since $\mathrm{g}=0$, differentiating Equation (7) and simplifying we have

$$
\Delta \underline{\underline{Q}}^{\mathrm{n}}=\Delta \underline{\epsilon}^{\mathrm{c}}-\mathbf{L}^{\mathrm{n}} \Delta \rho
$$

where

$$
L^{n}=\frac{3\left(\epsilon^{c^{n}}-\underline{\alpha}^{n}\right) \rho^{n}}{2\left(\epsilon^{c^{n}}-\underline{\alpha}^{n}\right)^{T}\left(\epsilon^{c^{n}}-\underline{\alpha}^{n}\right)} .
$$

Also differentiating Equation (3) we obtain an expression for $\Delta \mathrm{q}$ as follows

$$
\Delta q=\underline{H}_{1}{ }^{\mathrm{T}} \Delta \underline{g}+\underline{\mathrm{Q}}^{\mathrm{n}^{\mathrm{T}}}(\Delta \underline{\underline{\alpha}}-\Delta \underline{\underline{\xi}})+\Delta \rho
$$

where

$$
\underline{\mathrm{H}}^{\mathbf{n}^{\mathrm{T}}}=\frac{\partial \mathbf{q}}{\partial \boldsymbol{\alpha}}
$$

and

$$
{\underline{Q_{1}}}^{n^{T}}=\frac{\partial q}{\partial \underline{\alpha}^{n}}=-\frac{\partial q}{\partial \varepsilon^{c^{n}}} \text {. }
$$


Once $\Delta \rho$ is known, we can use Equations (16) to obtain $\Delta \underline{\xi}^{\mathrm{c}}$. Combining Equations (18) and (19), we have

$$
\Delta q=\underline{H}_{1}^{\mathrm{n}^{\mathrm{T}}} \Delta \underline{\mathrm{g}}+\left(1-\underline{\mathrm{Q}}^{\mathrm{n}^{\mathrm{T}}} \mathrm{L}^{\mathrm{q}}\right) \Delta \rho
$$

Analogous to the Equation (16) for $\Delta \xi^{c}, \Delta \rho$, can be expressed as

$$
\Delta \rho=\left[(1-\theta) \dot{\rho}^{n}+\dot{\rho}^{n+1} \theta\right] \Delta t
$$

Since $\rho^{n}=\rho^{n}\left(\xi^{c^{n}}, \eta^{n}\right)$, Equation (5), we have

$$
\dot{\rho}^{\mathrm{n}+1}=\dot{\rho}^{\mathrm{n}}+\underline{R}^{\mathbf{n}^{\mathrm{T}}} \Delta \dot{\boldsymbol{\epsilon}}^{\mathrm{c}}+\underline{R}^{\mathbf{a}^{\mathrm{T}}} \Delta \eta
$$

where

$$
{\underline{R_{1}}}^{n^{T}}=1^{n^{T}}=\frac{\partial \dot{p}^{n}}{\partial \dot{\xi}^{c^{n}}} \text { and } \underline{R}_{2}^{n^{T}}=\frac{\partial \dot{\boldsymbol{p}}^{\mathrm{n}}}{\partial n^{n}} .
$$

Also

$$
\Delta \dot{\underline{\dot{\epsilon}}}^{\mathrm{c}}={\underline{H_{0}}}^{\mathrm{a}} \Delta \underline{\boldsymbol{g}}+\underline{G}_{\mathrm{O}}{ }^{\mathrm{a}} \Delta \mathrm{q}
$$

as shown in Equation (17). Since $\eta_{i j}$ is a unit outward normal vector, $\eta_{i j} \eta_{i j}=1$, which upon differentiation yields $\Delta \mathfrak{\eta}=0$. Combining Equations (21) - (23), $\Delta \rho$ can be expressed as

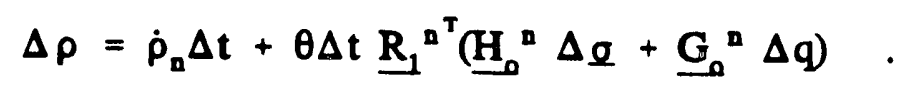

Now, using Equation (16) $\Delta \mathrm{q}$ can be expressed in terms of quantities that are known at time $\mathrm{t}^{\mathrm{n}}$ as follows

$$
\Delta q=\underline{R}^{\mathbf{n}^{\mathrm{T}}} \Delta \boldsymbol{Q}+\frac{1}{\gamma}\left(1-{\underline{Q_{1}}}^{\mathbf{D}^{\mathrm{T}}} \mathrm{L}^{\mathrm{q}}\right) \dot{\rho}_{\eta} \Delta \mathrm{t}
$$

where 


$$
\underline{R}_{3}^{n^{T}}=\left[\underline{H}_{1}^{n^{T}}+\theta \Delta+\left(1-\underline{Q}_{1}^{{ }^{T}} L^{\mathrm{D}}\right) \underline{R}_{1}^{n^{T}} \underline{H}_{0}{ }^{n}\right] \frac{1}{\gamma}
$$

and

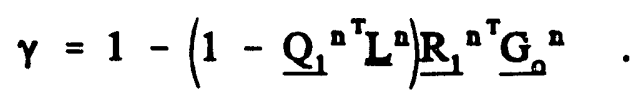

Combining Equations (25), (17) and (16) and substituting the result into Equation (13), we obtain $\hat{\mathbb{Z}}$ and $\underline{E}$ for the case when a point is on the CHS, that is, $\mathrm{g}=\mathbf{0}$ as follows

$$
\hat{\mathrm{D}}=\left[\mathrm{D}^{-1}+\theta \Delta t \underline{\mathrm{H}}_{0}^{\mathrm{n}}+(\theta \Delta t) \underline{G}_{0}{ }^{n} \underline{\mathrm{R}}_{3}^{{ }^{\mathrm{T}}}\right]^{-1}
$$

and

$$
E=\dot{\epsilon}^{c}+\frac{\theta \Delta t}{\gamma}\left[\underline{G}_{0}^{n}\left(1-Q_{1}^{n^{T}} L^{n}\right) \dot{p}_{n}\right]
$$

Case ii) Point inside the CHS, $\mathrm{g}<0$

Inside the CHS, as shown in Equation (5)

$$
\dot{\rho}^{\mathrm{n}}=\dot{\underline{\alpha}}^{\mathrm{n}}=0
$$

and, therefore,

$$
\Delta p=\Delta \underline{\alpha}=0 .
$$

Hence, Equation (19) for this case simplifies to

$$
\Delta q=\underline{H}_{1}^{{ }^{\mathrm{T}}} \Delta \boldsymbol{g}-\underline{\mathrm{Q}}^{\mathrm{n}^{\mathrm{T}}} \Delta \underline{\epsilon}^{\mathrm{c}} .
$$

Repeating the above procedure described for Case (i), we have the following expressions for $\hat{\mathbb{L}}$ and $E$ 


$$
\hat{\mathbf{L}}=\left[\underline{\mathbf{D}}^{-1}+\theta \Delta t \underline{\mathbf{R}} \underline{\mathbf{R}}_{\mathbf{G}}\right]^{-1}
$$

where

$$
\begin{gathered}
\underline{R}_{S}=\left[I-\theta \Delta t \underline{G}_{0}^{n} \underline{G}_{1}^{n}\right]^{-1} \\
\underline{R}_{d}=H_{0}^{n}+\underline{G}_{0}^{n} \underline{G}_{1}^{n^{T}}
\end{gathered}
$$

and $I$ is the identity matrix,

$$
\mathbf{E}=\underline{\mathbf{R}}_{\dot{\boldsymbol{\epsilon}}^{\mathbf{c}}}
$$

The expressions for the matrices $\mathrm{H}_{0}^{\mathrm{n}}, \mathrm{G}_{0}^{\mathrm{n}}, \mathrm{H}_{1}^{\mathrm{nT}}$, and $\mathrm{Q}_{1}^{\mathrm{nT}}$ in terms of the material constants and constitutive law are given below

$$
\begin{gathered}
\underline{H}_{1}^{n^{T}}=\frac{\left.\left(\epsilon^{c^{2}}\right)-\underline{\alpha}^{n}\right)^{T}}{\bar{\sigma}} \frac{\partial \underline{s}}{\partial \underline{\underline{\sigma}}}-\frac{3\left(q^{n}-\rho^{n}\right)}{2(\sigma)^{2}} \underline{s} \\
\underline{G}_{0}^{n}=\left(\frac{m-1}{m q}\right) \dot{\epsilon}^{c^{n}} \\
{\underline{Q_{1}}}^{n^{T}}=-\frac{\underline{s}}{\bar{\sigma}} \\
\underline{H}_{0}^{n}=\left(m-\frac{1}{m q}\right) \dot{\epsilon}^{c^{n} \underline{H}_{1}{ }^{T}}+\frac{3(n-m)}{2 m(\bar{\sigma})^{2}} \dot{\epsilon}^{c^{n}} s^{T}+C(\bar{\sigma}, q) \frac{\partial \underline{s}}{\partial \bar{\sigma}}
\end{gathered}
$$

Again, if the forward difference parameter $\theta$ is set equal to 0 in the above algorithm, it 
reduces to the explicit integration scheme, which does not guarantee a stablr convergent solution for all time step sizes.

\section{IMPLEMENTATION AND VERIFICATION OF THE ALGORITHM}

The algorithm described above has been implemented into the FE code FVP [3], which is already equipped to handle both time and strain hardening constitutive law's. The following features regarding the implementation of this method need to be highlighted:

i) If the corward difference parameter $\theta$ is set equal to 0 in the above algorithin, it reduces to the explicit integration scheme. Although this scheme dies lot guarantee a stable convergent solution for large time step sizes, sufficiently accurate solutions can be obtained for small step sizes. this will be shown in the following section.

ii) At time $\mathrm{t}=0$, upon application of the load, $\mathrm{q}=0$. Hence, from Equation (2) the strain rate $\xi^{c} \rightarrow \infty$ since $m<1$ for primary creep. Therefore, as is commonly done in such cases, for a short period of time, $8 \mathrm{t}$, an explicit time hardening law is used for the problem. Since the two laws are identical initially, this does not introduce any error in the solution procedure at later steps.

iii) At time $\mathrm{t}-\mathbf{8 t}$, upon obtaining an initial solution for the creep strains, the values for the center $\propto$ and the radius $\rho$ of the CHS have to be initialized. These values can be obtained from Equations (4) and (5) as follows

$$
\alpha_{i j}=\frac{1}{2} \epsilon_{i j}^{c}
$$

anı'

$$
\rho=\frac{1}{\sqrt{6}} \epsilon_{i j}^{c} \eta_{i j} .
$$

iv) The total creep strain at any time $t_{n}$ is computed by calculating the cumulative creep strain. 
This is computationally more efficient than using Equation (1) to determine $\epsilon^{\mathrm{c}}$.

v) On the CHS, even though $\mathrm{g}=0$ as shown in Equation (7), due to numerical error it is not exactly equal to 0 during the computational procedure. Therefore, it is difficult to determine if a given state of creep strain is exactly on the CHS or inside it. A better method to determine this in a computational scheme is to calculate the quantity

$$
G=\left(\epsilon_{i j}^{c}-\alpha_{i j}\right)\left(\epsilon_{i j}^{c}-\alpha_{i j}\right)
$$

at each time and compare it with its maximum value $G_{\max }$ evaluated throughout the previous time history. If $\mathrm{G} \geq \mathrm{G}_{\max }$ then a given point is on the CHS while $\mathrm{G}<\mathrm{G}_{\max }$ indicates that a point is inside it. Although mathematically the two methods are equivalent, numerically it is more efficient to do the latter.

vi) For all times $\mathrm{t}>\mathbf{8 t}$, large time steps $\Delta \mathrm{t}$ can be taken in the solution procedure since an implicit scheme is used. When the applied load is changed, however, the elastic solution is recomputed so that the elastic component of the total strain corresponds to the new load. As is done upon initial loading, after a load change a solution is first obtained for a small time step of $8 \mathrm{t}$, after which the computations using large time steps are resumed.

vii) The Elaborate Theory described by Equation (8) - (10) as well as the modification to hancile anelastic recovery, Equations (11)- - (12) have been incorporated into the code using the explicit scheme $\theta=0$. Since it is expected that the Simple Theory will work satisfactorily for most cases of interest in this work [2], only a few computations using the two extensions may be necessary in studying creep crack growth. These can be done using the explicit scheme, thus avoiding the complexities of developing separate implicit algorithms for these models.

Once the algorithm involving the Simple Theory was implemented, the numerical results were verified using closed form solutions to Equation (2) for the case of uniaxial tensile stress and pure shear stress involving three fully reversed load steps. Figures $2 \mathrm{a}$ and $2 \mathrm{~b}$ show the FE mesh and the boundary conditions used to simulate pure tension and pure shear loads respectively. Figures $3 \mathrm{a}$ and $3 \mathrm{~b}$ show a comparison of the non-dimensionalized strain as predicted by the FE results (using both explicit and implicit schemes) with the closed form solution. Time 
steps $\Delta \mathrm{t}-0.5$ hours were used in this case. As seen, the FE results using the implicit scheme are in excellent agreement with the exact solution. Also, as would be expected, the implicit scheme yields more accurate results than the explicit scheme for the same time step size.

The error in the solution procedure is influenced significantly by the size of the time step $\Delta \mathrm{t}$. Figures $4 \mathrm{a}$ and $4 \mathrm{~b}$ show results for the same load cases discussed above but with time step sizes $t=0.1,0.25,0.5,1.0$ and the implicit integration scheme. As seen, the error introduced in the numerical procedure decreases as the step size is reduced for the tension case and is insensitive to $\Delta t$ for the shear case. For very small step sizes, for example $\Delta t=0.1$ in this case, both the implicit and explicit methods are equally accurate. Such errors have been shown to vary inversely with the number of steps used to reach time $t^{\mathrm{n}}$ by Krishnaswamy [14].

\section{COMPARISON WITH EXPERIMENTAL RESULTS}

The numerical predictions from the FE analysis will now be compared with experimental data for repeated multiaxial loading histories of Murakami and Ohno [2]. The details of these experıments conducted on thin-walled tubes of Type 304 stainless steel at 650 degrees $C$ under combined tension and torsion loads are given in Reference [2]. The material constants $\mathrm{A}, \mathrm{m}$, and $\mathrm{n}$ for the Simple Theory described above obtained from pure shear (torsion) tests at stress levels of $\sqrt{3} \sigma_{12}=117.7,137.3$ and $156.9 \mathrm{MPa}$ where $\mathrm{A}=3.1 \times 10^{-19}, \mathrm{~m}=0.54$, and $n=7.2$. For each test the change in the principal stress direction $\theta$ due to a change in load is given by

$$
\operatorname{Cos} \theta=s_{\mathrm{ij}} s_{\mathrm{ij}}^{*} /\left(s_{\mathrm{kl}} s_{\mathrm{kl}} s_{\mathrm{mn}}^{*} s_{\mathrm{mn}}^{*}\right)^{1 / 2}
$$

where $s_{\mathrm{ij}}$ and $s_{\mathrm{ij}}^{*}$ are the different states of deviatoric stress.

Figure 5 shows a comparison between the numerical and experimental results for the case of cyclic torsional loading $(\theta=180$ degrees) using both the Simple Theory as well as the conventional Strain-Hardening Theory. The implicit scheme with time steps $\Delta t=0.5$ hours was used in all cases. As seen, the Simple Theory is significantly better than the conventional model in predicting experiments. For cases where $\theta=150,90$, and 30 degrees, the results are shown in Figures 6, 7, and 8, respectively. In all cases, the Simple Theory matches experimental observations significantly better.

For $\theta=150$ degrees, additional computations using the Elaborate Theory were 
also performed using both the explicit and the existing implicit scheme. Additional material constants $\zeta=2.1$ and $\xi=0.25$ are necessary to account for non-coaxiality between the creep strain rates and deviatoric stresses for this model. As would be expected, the numerical predictions of this theory are better than those for the Simple Theory, Figure 9. Since a separate implicit algorithm was not developed for the Elaborate Theory, the predictions of the implicit scheme are not as accurate as those for the explicit scheme ( $\Delta t=0.1$ hours).

Results for both the Simple and Elaborate Theory using the FE algorithm are in excellent agreement with those presentec by Murakami and Ohno [2] for the cases discussed above.

\section{THE USE OF INTEGD A I FIRACTURE PARAMETERS FOR CREEP
CRACK GROWTH}

The creep crack growth process is studied in the following section by performing analyses of creep crack growth experiments. The creep crack growth experiments are constant load tests, which are the focus of the Phase I effort for this program. The experimental data is from a state-of-the-art document from the VAMAS group conference [4]. The VAMAS report provides a detailed compilation of creep material and crack growth data. In addition, the preseritly accepted procedures for evaluation of creep crack growth in constant load structures as agr:ed upon by the VAMAS group experts is presented. This presently accepted method, which is oased on the $C_{t}$ parameter of Saxena $[1,16]$ will not be appropriate for the history dependent load cases to be examined in the Phase II and Phase III efforts. Hence, in addition to the new creep fracture parameters which are being studied in this program, the ability of the presently accep:- $d$ methods will be considered. In this fashion, it may be possible to extend the simple engineering analysis procedures to be applicable for the severe load cases being considered in this program.

This section first provides a description of many of the parameters which are being considered in this program. Second'y, the results for the stationary crack problem are provided. This will allow us to verify our finite element analysis procedure accuracy by tying into known solutions for the stationary crack problem. Finally, results are presented for the growing crack problem. This is done by modeling one of the experiments from the VAMAS report.

The results presented here provide results from the specialization of the MurakamiOhno law to a secondary (Norton) creep law. Additionally, the present results represent the analysis of one test from Reference [4]. Results from other tests are currently being produced 
using the many different forms that the Murakami-Ohno model may take, from simple theory through the complicated form. These results from different tests (which experience different conditions) will be used to identify which parameters are valid for use in constant load creep crack growth. The most promising parameters will be more extensively examined and further developed in the Phase II and III effort. In this fashion, a rational high temperature fracture theory valid for severe load conditions is being developed.

\subsection{Creep Fracture Parameters}

Perhaps the most promising practical engineering approach to predicting the crack growth behavior of cracked solids that undergo time dependent straining is the $\mathrm{C}_{\mathrm{t}}$ parameter approach developed by Saxena $[1,16]$. This approach may be described as follows. From a series of creep experiments on laboratory specimens a simple functional relationship is developed between creep crack growth rate, $a \mathrm{a} \equiv \mathrm{da} / \mathrm{dt}$, and $\mathrm{C}_{\mathrm{t}}$. With $\mathrm{C}_{\mathrm{t}}$ theory, this relationship defines the material crack growth law. With this material crack growth law defined, the life of an engineering component is predicted by integrating the creep crack growth law with respect to time using an estimate of $\mathrm{C}_{\mathrm{t}}$.

The simplicity of the $C_{t}$ approach is quite appealing to the practicing engineer. Two difficulties with this approach currently being addressed in the literature are: predicting the service value of $C_{t}$ versus time in the engineering component of interest and based upon a constitutive theory of an elastic-secondary creep model. The $C_{t}$ approach, however, is applicable only to simple (constant load) conditions, although it is routinely used beyond its applicable range.

An alternative approach considered here is based upon using integral parameters to characterize the creep crack growth process. This method may' be described as follows. A material resistance curve is developed by performing an experiment on a laboratory fracture specimen. The experiment is then modeled via the finite element method where the integral parameter(s) of interest are calculated along a small finite-sized path. This numerical experiment then produces the material resistance curve(s). The behavior of other arbitrarily loaded and cracked structures can then be predicted by modeling the time history of loading and using this generated resistance curve as a crack growth criterion. The resistance curve is assumed to be an intrinsic material property. The time history of crack initiation and growth may thus be predicted. The analogy to elastic-plastic fracture mechanics based upon the J-integral may be made. A 
disadvantage of this approach is that currently a finite element solution is required to apply the technique.

A number of time dependent crack tip parameters expressed in integral forms have appeared in the literature. These include Blackburn [17] $\left(\dot{J}_{B}\right)$; Kishimoto, Aoki, and Sakata [18] (J) ; McClintock [19] ( $\left.\dot{J}_{M}\right)$; Watanabe [20] $\left(\dot{J}_{W}\right)$; Goldman and Hutchinson [21] (C*); Brust and Atluri [22] $\left(\mathrm{T}^{*}\right)$; and others. If an asymptotic crack tip solution with a free amplitude parameter exists (as for a stationary crack), then it can be shown that the strength of the field can be written in terms of the chosen integral, as long as the integral is of order $0\left(\frac{1}{r}\right)$.

The superimposed "dot" above these parameters signifies the material rate, and the total form is obtained via tin. ${ }^{\circ}$ integration. The physical interpretation of many of these integral parameters is not entirely clear except for the $T^{*}$. Brust, Nakagaki and Gilles [23] showed that the physical interpretation of the $\mathrm{T}^{*}$ integral is that of the energy release rate to a finite sized material volume in the vicinity of the crack tip. The ability of the $T^{*}$ integral and other parameters to characterize nonlinear fracture have been documented in Reference [23] and many references cited therein. The finite element implementation of these parameters is discussed by Brust, Nakagaki, and Springfield [24].

Finally, the NASA Lewis (and their engine subcontractors) have experienced great success in attempting to use integral parameters to characteriz: high temperature severe load (creep-fatigue) conditions [25]. The NASA approach is to develop a simple engine fatigue life design procedure by writing the crack growth rate per load cycle as a simple function of the change in integral parameter. This results in a simple extension of classical fatigue life prediction based on the stress intensity factor or J-integral. While our approach is fundamentally much different from theirs, this result gives us great hope in achieving success here.

\subsection{Results - Stationary Crack}

A standard compact tension specimen of width $50.8 \mathrm{~mm}$, thickness $6.35 \mathrm{~mm}$, and crack length over width ratio of 0.516 was discretized into 8-noded isoparametric finite elements (See Figure (10)). A small deformation plane stress analysis was performed using an elastic-power law creep equation described by:

$$
\dot{\boldsymbol{\epsilon}}=\frac{\dot{\boldsymbol{t}}}{\mathrm{E}}+\mathbf{A} \tau^{\mathbf{n}}
$$


This represents a special case oi the Murakami-Ohno creep law discussed in Section 3. Here $\epsilon$ represents total strain, $\tau=$ stress, $E=129.5 \mathrm{MPa}, \mathrm{n}=5.6$, and $\mathrm{A}=6.46 \times 10^{-18}(\mathrm{MPa})^{-\mathrm{n}} \cdot \mathrm{hr}^{-1}$. These represent material properties of ASTM grade A470 class $81 \mathrm{Cr}-1 \mathrm{Mo}-0.25 \mathrm{~V}$ of the ASTM Task Group report [1] and the VAMAS report [4]. A load of $1.7 \mathrm{kN}$ was applied wherein initially elastic response occurred. The specimen was permitted to creep until steady-state conditions were achieved at constant crack length. All of the integral parameters described earlier were calculated.

Figure 11 shows the near-crack-tip ficld and far field value of $C^{*}$ calculated via the line integral definition, along with the rate form of the $T^{*}$ integral $\left(T^{\circ}\right)$, and $C_{t}$ evaluated via the experimental formula for small-scale creep

$$
C_{t}=\frac{P V_{c}}{B W} G(a / w)
$$

In the above equation $P$ is load, $\dot{V}_{c}$ is the current load-line displacement rate due to cr sep alone, B is thickness, W is specimen width, and $G(a / w)$ is solely a function of geometry (given in Reference [4]).

At early times transient creep effects are quite important, as seen by observing the path dependence of $C^{\circ}$. Note that the far field $C^{*}$-integral compares quite well with $C_{t}$ for time greater than about 2 hours even though steady state is not achieved until about 20 hours. At steady state $C^{*}$ becomes path independent and equivalent to $C_{t}$ while $T^{*}$ is slightly higher than $C^{*}$. The value of $C^{*}$ compares well with the known solution from the engineering handbooks verifying the analysis procedure. The behavior of the rate forms of the other integral parameters is presented in Figure 12. Note that the numerical values of all of these integrals differ throughout the time history. $\mathcal{S}$ and $\dot{J}_{M}$ initially rise from negative values at very small times where transient effects are significant. At very small times nonsteady state conditions dominate, hence the rate form of any characterizing parameter should be non-negative. This seems to indicate that the $T^{\circ}$ and $J_{W}$ integrals behave more realistically than the other integral parameters. Figure 12 shows the development of the creep zone size ligament. It is seen that a contained creep zone exists until the zone rapidly extends across the entire ligament for times greater than $\mathbf{3 0}$ hours. Note 
that, despite this, the steady state value of the $C^{*}$ integral and $\dot{T}^{*}$ approach their steady state values (constant rate) at times much less than this; i.e., at about 10 hours.

\subsection{Results - Growing Crack}

The standard compact tension specimen, which was described above in Section 6.2, was again analyzed, including crack growth. The experimental load of $1.7 \mathrm{KN}$ was applied and the experimentally produced crack growth versus time history was modeled. The test was conducted at 538 degrees $\mathrm{C}$. The Murakami-Ohno constitutive law and the material properties were specified to produce a Norton creep law. The Norton law parameters are listed in Section 6.2 .

A comparison between predicted and experimentally measured load line displacement versus time is illustrated in Figure 14. It is seen that a very good comparison between experiment and analysis is produced throughout most of the time history. This good comparison occurred despite the fact that simple Norton creep constitutive law was used. However, it will be seen shortly that while far field quantities may be predicted reasonably well using a simple constitutive law, quantities evaluated near the crack tip, such as integral parameters, are inaccurate. Indeed, the $\mathrm{T}^{*}$-integral has a known energy interpretation, and the other parameters are related to energy dissipation. Clearly, for a growing crack, the amount of energy dissipation in the vicinity of the crack tip will depend strongly on the constitutive response of the material in the crack tip region. This effect is being seen as we continue to analyze this specimen and othier test specimens from References [1] and [14].

The behavior of the $C_{t}$ parameter, evaluated via Equation (32), is compared with the $\mathrm{C}^{*}$ integral, evaluated on a path very close to the crack tip, in Figure 15 . The $\mathrm{C}^{*}$ integral was evaluated on numerous paths which encompassed the growing crack tip and was very much path dependent. Interestingly, the far field $C_{t}$ value compares very well with the near field $C^{*}$ integral. This suggests that the far field experimentally evaluated $C_{t}$ parameter is directly related to near field damage processes. This may be one reason that the $C_{t}$ parameter has been successful in characterizing constant load creep crack growth data to engineering accuracy. When steady state creep conditions are experienced throughout the body, the $\mathrm{C}^{*}$ integral becomes nearly path independent (for slow crack growth) and, hence, $C_{t}=C^{*}$. However, such good comparison is not expected under the history dependent loading conditions to be examined in Phase II. 
The behaviors of total integrated values for five integral parameters are illustrated in Figures 16-18 for different path radii. The path radius is defined as the distance from the crack tip where the line integral passes in a direction perpendicular to the crack growth direction. For the stationary crack (before crack growth commences), this also represents the radial distance ahead of the crack tip. As the crack grows, the path extends in a "Dugdale" fashion, as fully discussed in Reference [23]. As seen in Figures 16-18, the values of all of the integral parameters increase as the path size radius increases from $R=0.45 \mathrm{~mm}$ (Figure 16) to $R=0.8 \mathrm{~mm}$ (Figure 18). Note from these figures that the integrals begin to decrease at large times. As alluded to above, this is apparently a consequence of using an inappropriate constitutive law (Norton power law creep). Preliminary results of ongoing analyses using the Murakami-Ohno constitutive law indicate that the $\mathrm{T}^{*}$ integral levels off to a constant value after a certain amount of crack growth. This is to be expected, as discussed in Reference [23] in the context of elastic plastic crack growth using the $T^{*}$ integral. At minimum, though, for these parameters to be useful they must be nondecreasing.

The analyses of this experiment continues using time hardening, strain hardening, and the Murakami-Ohno constitutive laws. In addition, three additional experiments from Reference [4], which represent the same material but under different creep crack growth conditions, are being identically analyzed. All of the above parameters, including $C_{t}$ and $C^{*}$, are being evaluated. The integral parameters are being compared between the different tests (in terms of parameter versus crack growth) to evaluate which parameters are invariant and, hence, represent an intrinsic material property. All such analyses are being completed as part of the Phase I effort. This will lead naturally into the Phase II load cases, which interrogate the parameters much more closely.

\section{CONCLUSIONS TO DATE}

A new and powerful tool has been developed here that enables the analysis of creep crack growth in structures that experience variable load history. This methodology involves i) the use of an existing sophisticated constitutive model based on the CHS that described the nonlinear, history-dependent material behavior during transient creep accurately; and, ii) a newly developed implicit FE algorithm for this model that ensures a stable convergent solution or large time steps. 
The method presented here has been verified for simple uniaxial and shear problems by comparing numerical results with closed-form solutions. The influence of time step size on the error has been studied.

Analyses of a compilation of constant-load-creep-crack-growth tests using the above described constitutive law continues as the Phase I effort is completed. The analysis results for these specimens will be completed and documented by the end of the Phase I effort.

\section{PRESENTATIONS AND PUBLICATIONS}

The first portion of this repoit will be sent to the International Journal for Numerical Methods in Engineering for publication by the end of November, 1991. The second portion of the report, describing creep crack growth studies, will be submitted to a fracture mechanics journal early in 1992, after results are finalized and verified. Additionally, the results will be presented at two conf 'rences during 1991. Hence, two publications and two presentations will result from the Phase I effort.

\section{DISCUSSION OF FUTURE WORK}

No significant deviation from the originally proposed work is expected. Upon completion of Phase I, Phase II will begin and consists of two tasks. Task 1 involves variable load history tests while Task 2 involves using the integral parameters to predict crack growth versus time to failure response measured in the experiments.

\section{PHASE II. EXPERIMENTS AND VALIDATION}

\section{Task 1. Variable Load Creep Experiments}

The Phase II text matrix is listed in Table 1. The load history of Figure 19 will be employed. 
TABLE 1. VARIABLE LOAD CREEP TEST MATRIX

\begin{tabular}{|c|c|c|c|c|c|c||}
\hline \hline Test Number & $\mathrm{P}_{0}$ & $\mathrm{t}_{1}$ & $\mathrm{P}_{1}$ & $\mathrm{t}_{2}$ & $\mathrm{P}_{2}$ & $\mathrm{a}_{\mathrm{o}} / \mathrm{W}$ \\
\hline CT 2.1 & $0.5 \overline{\mathrm{P}}$ & $0.1 \tau$ & 0 & $\tau$ & $0.5 \overline{\mathrm{P}}$ & 0.5 \\
\hline CT 2.2 & $0.65 \overline{\mathrm{P}}$ & $\tau$ & 0 & $0.1 \tau$ & $0.66 \overline{\mathrm{P}}$ & 0.25 \\
\hline CT 2.3 & $0.80 \overline{\mathrm{P}}$ & $4 \tau$ & 0 & $\tau$ & $0.80 \overline{\mathrm{P}}$ & 0.25 \\
\hline
\end{tabular}

$1 \quad \bar{P}$ is the iimit load.

$2 a_{0}=$ initial crack length: $W=$ specimen width.

$3 \tau$ is transition time (estimated via Riedel-Rice) between small scale and extensive specimen creep.

As illustrated in Figure 19, each will be subjected to a different load time history. The Xs marked $B$ and $C$ in Figure 19 depict times when, after unloading and/or reloading occurs, crack growth again recurs. The hold time $t_{2}-t_{1}$ will influence when crack growth will occur again. The load time histories are chosen so that different results are obtained for each of the specimens.

The text matrix of Table 1 ensures that three markedly different load histories, and corresponding crack-tip damage, will be experienced by each specimen. During the initial load (to $P_{0}$ ) each specimen will encounter different time-independent plastic zones since the load levels are different. During the initial hold period (to time $t_{1}$ ) different amounts of creep damage and corresponding crack growth will occur between specimens. At time $t_{1}$, when the specimen is unloaded, each specimen will experience different amounts of reverse time-independent damage. During the hold period $\left(t_{2}-t_{1}\right)$ different amounts of stress relaxation at the crack tip will occur. At final loading to $\mathrm{P}_{2}$, the instantaneous time-independent deformation, which occurs on top of all previous damage, differs between specimen. Finally, the amount of sujsequent crack growth and time to failure during the final hold period will differ. Hence, it is seen that these tests were chosen so that the predictions made using the two methods (one damage based, one integral parameter) will clearly identify which method is capable of accounting for history dependent damage.

Finally, we show some results recently produced at Battelle, which illustrate the importance of considering history dependent damage. Transient crack growth experiments on a 9CR-1Mo-V-Nb steel using the loading spectrum shown in Figure 20 was performed. Significant 
displacement recovery was observed during the unloading portions of the cycles, even at zero load, implying the role of accelerated primary creep under load reversals. Also, the load-point displacement rates were high immediately on reloading; the rates settled down to lower values with time. Figure 21 illustrates the load, load-point displacement, and crack length (measured by electric potential, EP) data corresponding to the loading spectrum shown in Figure 20 . the inelastic displacement rates were significantly higher than simple predictions based on secondary creep, implying the importance of primary creep. Also, crack growth rates were higher than corresponding creep-crack growth (CCG) rates when $\mathrm{C}^{*}$ was used as the characterizing parameter. Clearly, a more accurate analysis is required, which will be addressed in the Task 2 analysis efforts.

\section{Task 2. Analysis}

The integral parameters and damage-based techniques, as identified by the results on the Phase I study and improved as necessary, will be used to predict the crack growth versus time to failure response measured in the Phase II experiments. The predicted results will be compared to experimental results as shown in Figure 22. In addition, simplified solution techniques which do not require numerical simulation will be considered. These analyses probably will result in the implementation of a fourth constitutive model into the finite element code during Phase II.

10. REFERENCES

1. Leung, C. P., McDowell, D. L., and Saxena, A., "Influence of Primary Creep in the Estimation of C Parameter", EPRI Topical Report, Contract 2253-10, August, 1988.

2. Murakami, S. and Ohno., N. "A Constitutive Equation of Creep Based On The concept Of A Creep Hardening Surface, Int. J. of Solids and Structures, Vol. 18, No. 67, pp. 597 609, 1982.

3. Brust, F. W., FVP-A Finite Element Program For Viscoplastic Materials, Battelle, 1991.

4. Gibbons, T. B., editor, "Creep Crack Growth, A State Of The Art Report”, VAMAS (Versailles Project on Advanced Materials and Standards) task group report, February, 1989.

5. Watanabe, O. and Atluri, S. N., "Internal Time, General Internal Variable and MultiYield-Surface Theories of Plasticity and Creep: A Unification of Concepts", Int. J. Plast., Vol. 2, No. 1, pp. 37-69, 1986. 
6. Lindholm, U. S., Chan, K. S., Bodner, S. R., Weber, R. M., Walker, K. P., and Cassenti, B. N., "Constitutive Modeling for Isotropic Materials (HOST)", Prepared for NASA Lewis by SWRI, NASA Cr-174718, May 1984.

7. Ohno, N., Murakami, S. and Ueno, T., “A Constitutive Model of Creep Describing Creep Recovery and Material Softening Caused by Stress Reversals”, J. Engineering Materials and Technology, Vol. 107, pp. 1-6, 1985.

8. Inoue, T., et al., "Evaluation of Inelastic Constitutive Models Under Plasticity-Creep Interaction For 2-1/4 Cr-1Mo Steel at $600^{\circ} \mathrm{C}^{\prime}$, Nuclear Engineering and Design, Vol. 114, pp. 295-309, 1989.

9. Brust, F. W., McGowan, J. J., and Atluri, S. N., "A Combined Numerical/Experimental Study of Ductile Crack Growth After A Large Unloading Using T, J, and CTOA Criteria”, Engineering Fracture Mechanics, Vol. 23, No. 3, pp. 537-550, 1986.

10. Inoue, T., "Inelastic Behavior of 2-1/4 Cr-1Mo Steel Under Plasticity-Creep Interaction Condition", Nuclear Engineering and Design, Vol. 90, pp. 287-297, 1985.

11. Chaboche, J. L., "Viscoelastic Constitutive Equations For The Description of Cyclic and Anisotropic Behaviour of Metals", Bull. Acad. Polon. Sci., Ser. Sci. Tech., Vol. 25, page 33, 1977.

12. Miller, A., "An Inelastic Corstitutive Model for Monotonic, Cyclic and Creep Deformation”, ASME J. Engng. Mat. Tech., Vol. 98, page 97, 1976.

13. Owen, D. R. J. and Hinton, “Finite Elements in Plasticity”, Pineridge Press, 1980.

14. Inoue, T., et al., "Evaluation of Inelastic Constitutive Models Under Plasticity-Creep Interaction in Multiaxial Stress State", Nuclear Engineering and Design, Vol. 126, pp. 1-11, 1991.

15. Krishnaswamy, P., "Time Dependent Deformation and Fracture of Ductile Polymers: A Finite Element Approach”, Ph.D. Thesis, University of Washington, 1990.

16. Saxena, A., in Fracture Mechanics, Seventeenth Volume, ASTM STP 905, pp. 185-201, 1986.

17. Blackburn, W. S., "Path Independent Integrals to Predict Onset of Crack Instability in an Elastic Plastic Material”, Int. Journal of Fracture Mech., Vol. 8, pp. 343-346, 1972.

18. Kishimoto, K., Aoki, S., and Sakata, M., "On the Path-Independent Integral- $\hat{\text { ", }}$ Engineering Fracture Mechanics, Vol. 13, pp. 841-850, 1980.

19. McClintock, F. A., in Fracture 3, Ed. H. Liebowitz, Academic Press, 1971. 
20. Watanabe, K., “The Conservation Law Related to Path Independent Integral and Expression of Crack Energy Density by Path Independent Integral”, Bull. of JSME, Vol. 28, No. 235, January 1985.

21. Goldman, N. L. and Hutchinson, J. W., "Fully-Plastic Crack Problems: The Center Cracked Strip Under Plane Strain”, Int. J. of Solids and Struct., vol. 11, No. 5, pp. 575-592, 1975.

22. Brust, F. W. and Atluri, S. N., "',tudies on Creep Crack Growth Using the $\dot{T}^{*}$ Integral", Engineering Fracture Mechanics, Vol. 23, No. 3, pp. 551-574, 1986.

23. Brtst, F. W., Nakagaki, M., and Gilies, P., "Comparison of Elastic-Plastic Fracture Mechanics Techniques", ASTM STP 1074, pp. 448-469, 1990.

24. Brust, F. W., Nakagaki, M., and Springfield, C. W., "Integral Parameters For Thermal Fracture", Engineering Fracture Mechanics, Vol. 33, No. 4, pp. 561-579, 1989.

25. Kim, K. S., et al., "Elevated Temperature Crack Growth", Final Report to NASA Lewis Research Center, November, 1988. 


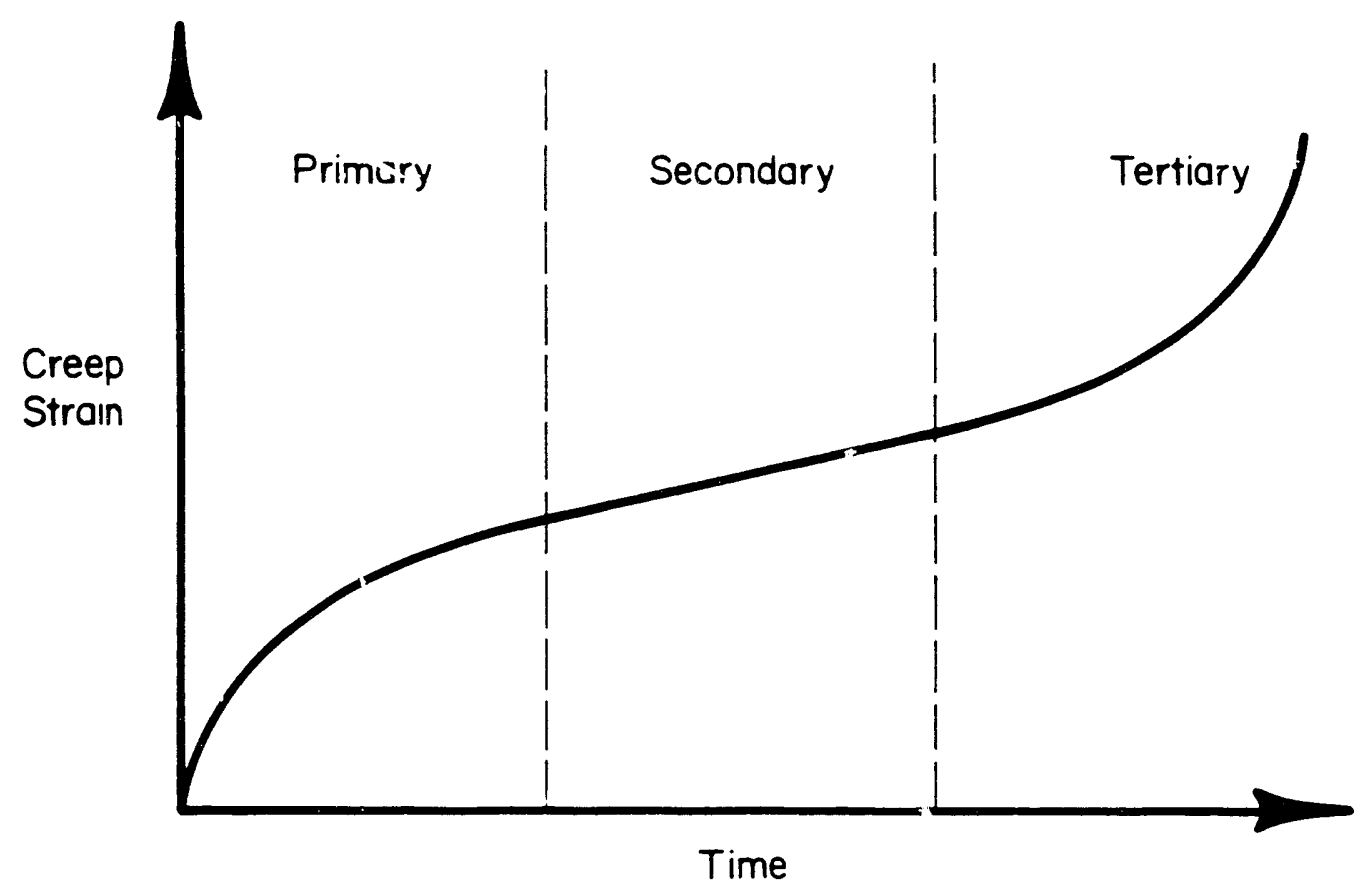

FIGURE 1a. TYPICAL CREEP STRAIN VERSUS TIME CURVE

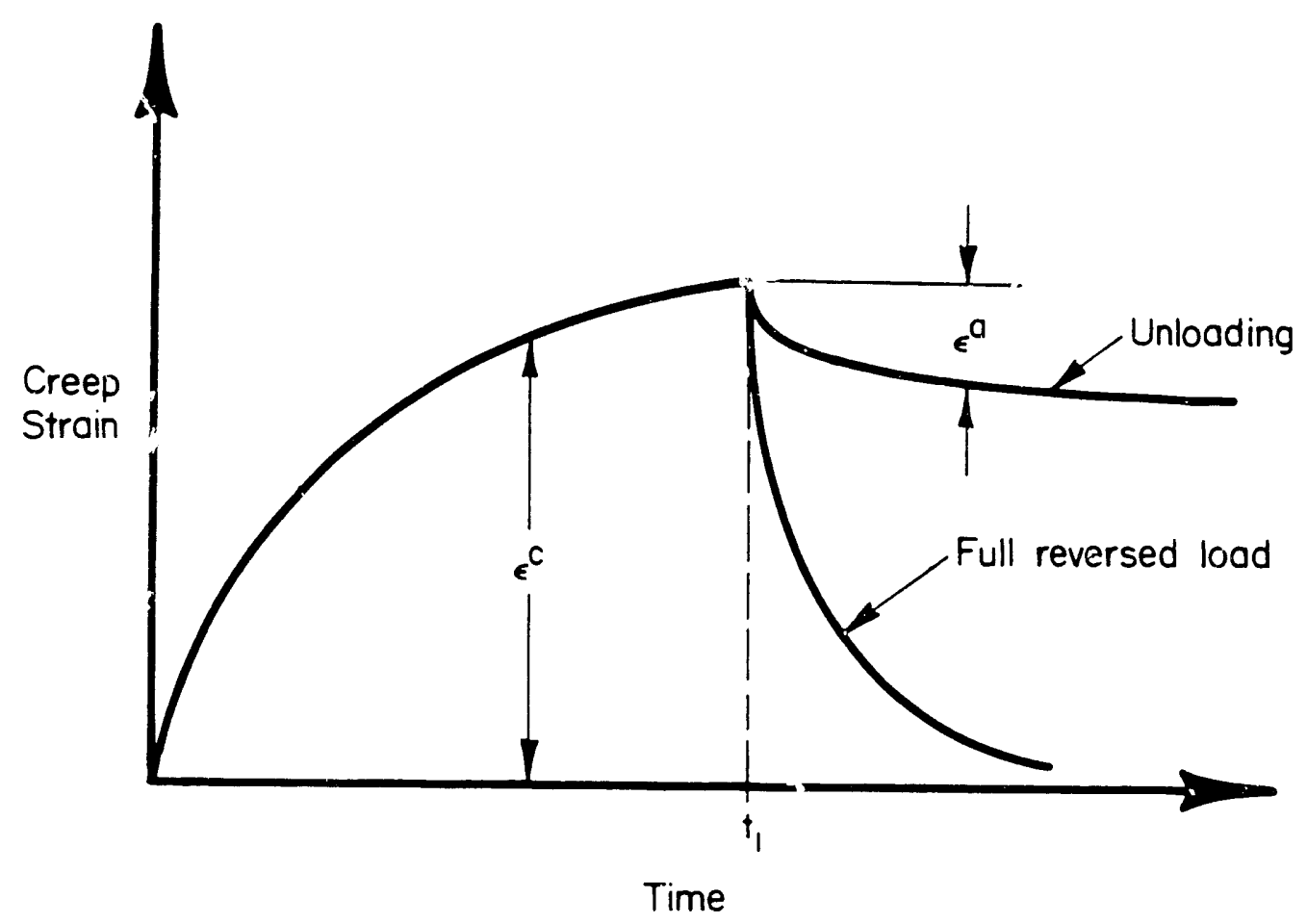

FIGURE 1b. TYPICAL CREEP STRAIN VERSUS TIME SHOWING UNLOADING AND REVERSED LOADING AT TIME $\mathrm{T}_{1}$ 


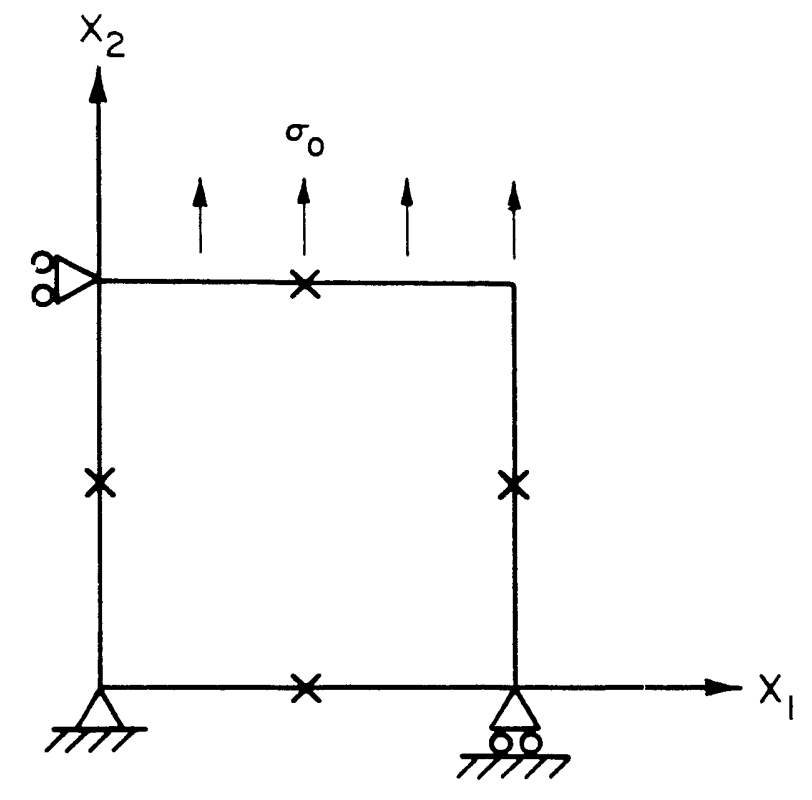

(a)

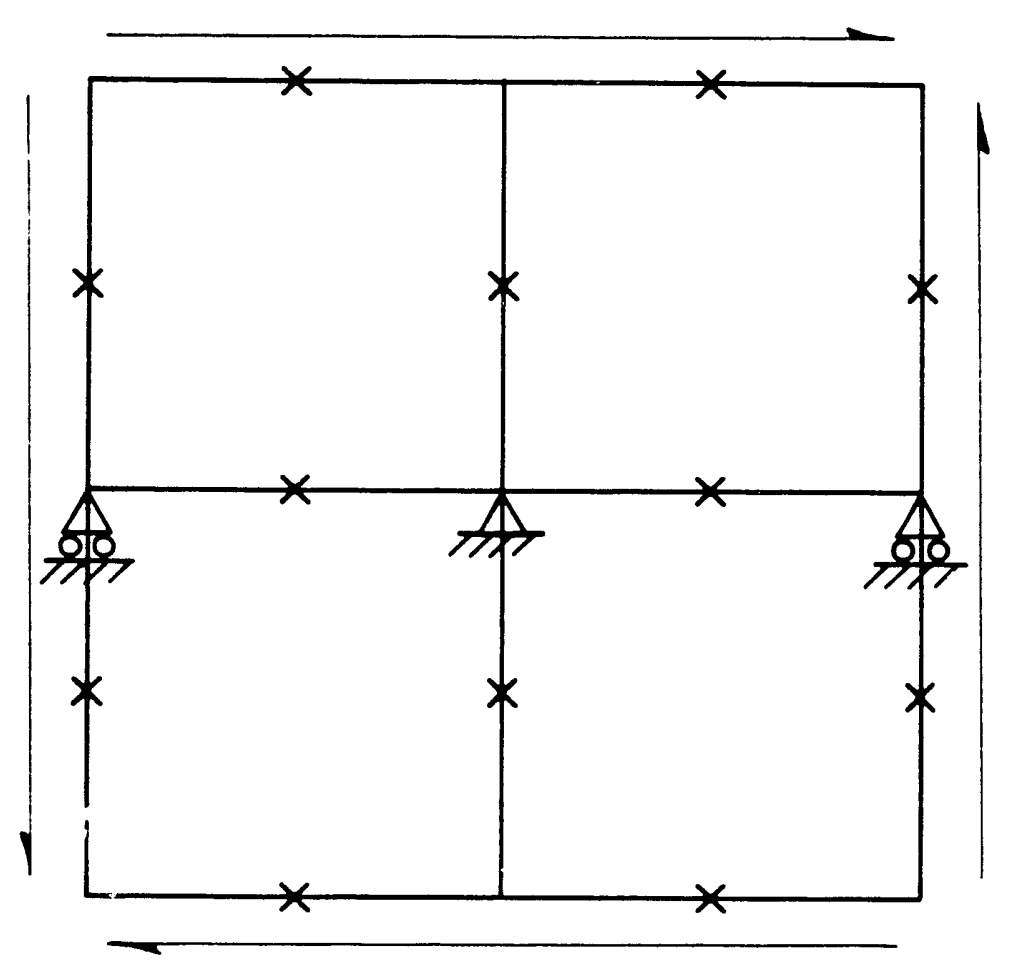

(b)

FIGURE 2. FE MESH SHOWING BOUNDARY CONDITIONS FOR (a) UNIAXIAL TENSION AND (b) PURE SHEAR 


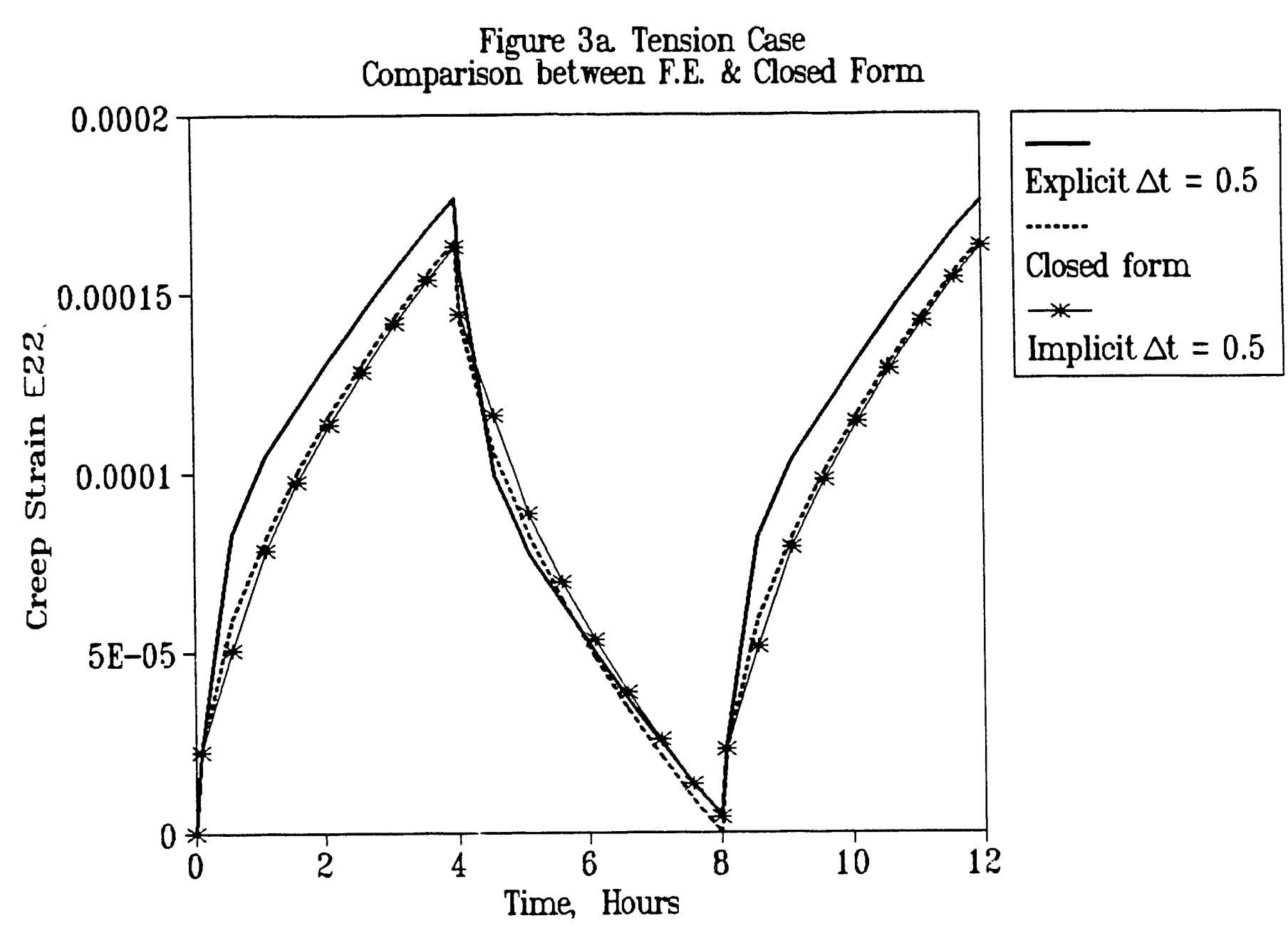

FIGURE 3a. COMPARISON BETWEEN FE PREDICTION AND EXACT SOLUTION FOR UNIAXIAL TENSION 


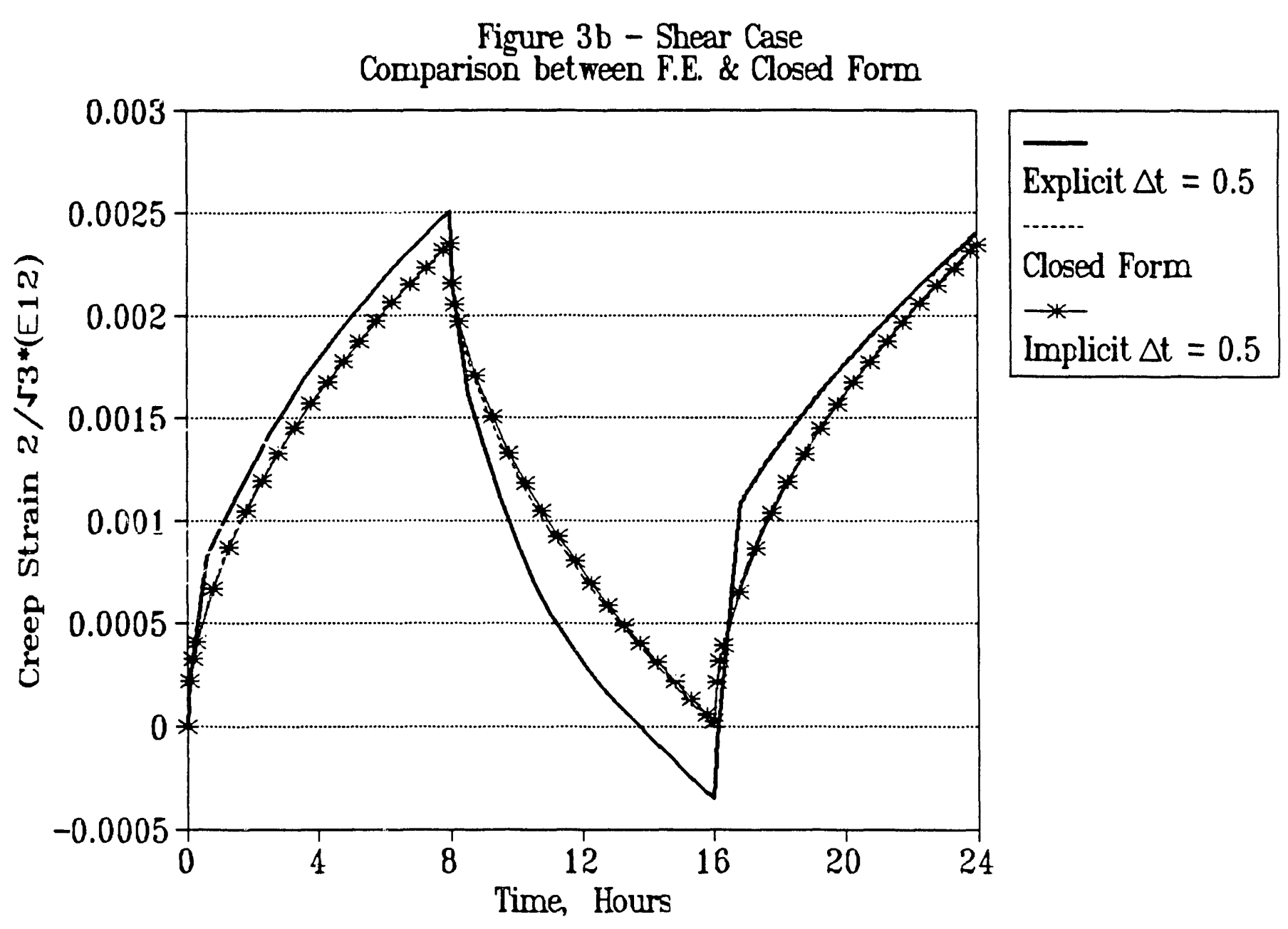

FIGURE 3b. COMPARISON BETWEEN FE PREDICTION AND EXACT SOLUTION FOR THE PURE SHEAR CASE 


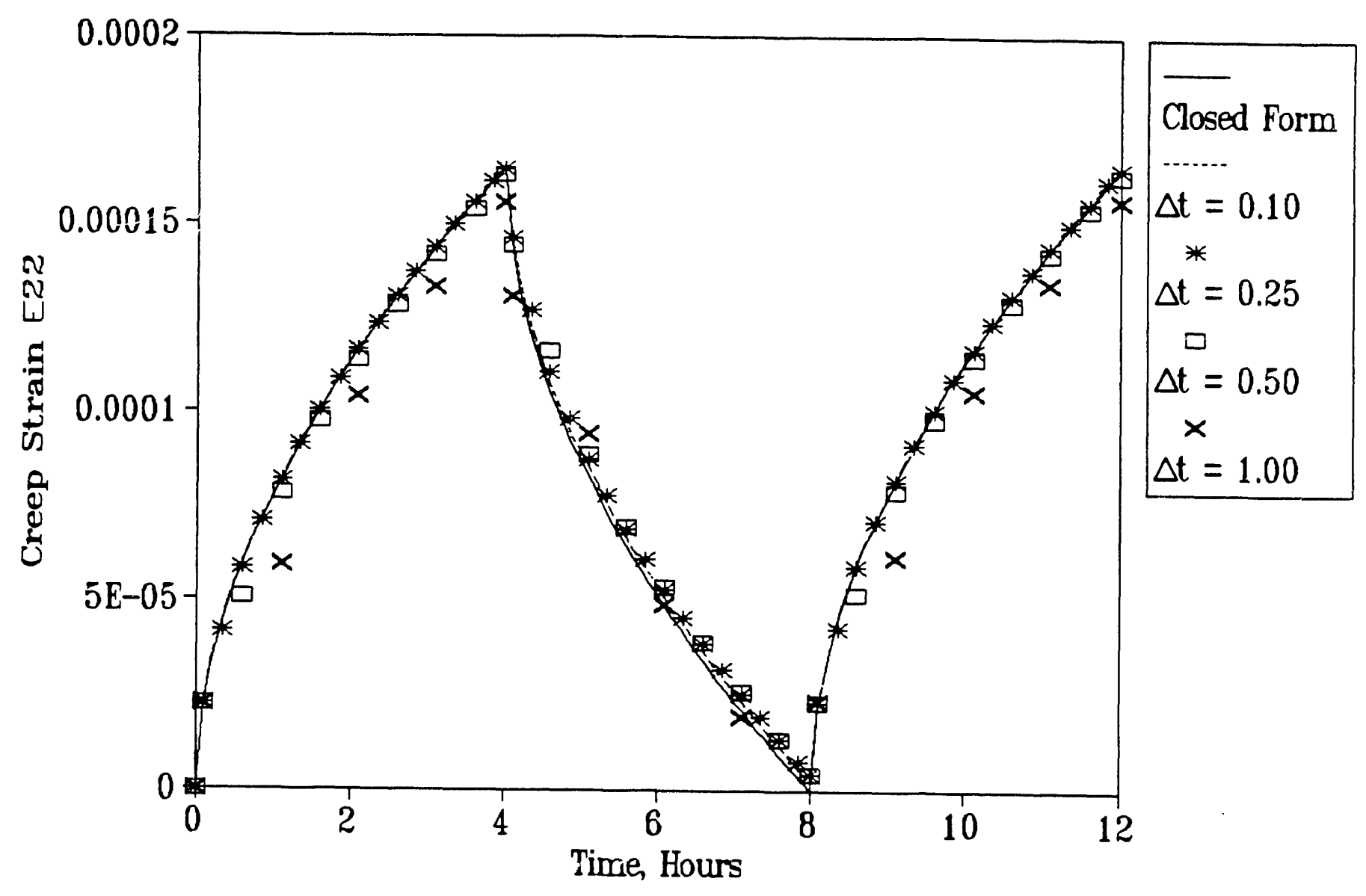

FIGURE 4a. EFFECT OF TIME STEP SIZE $\triangle$ T ON FE PREDICTIONS FOR UNIAXIAL TENSION 


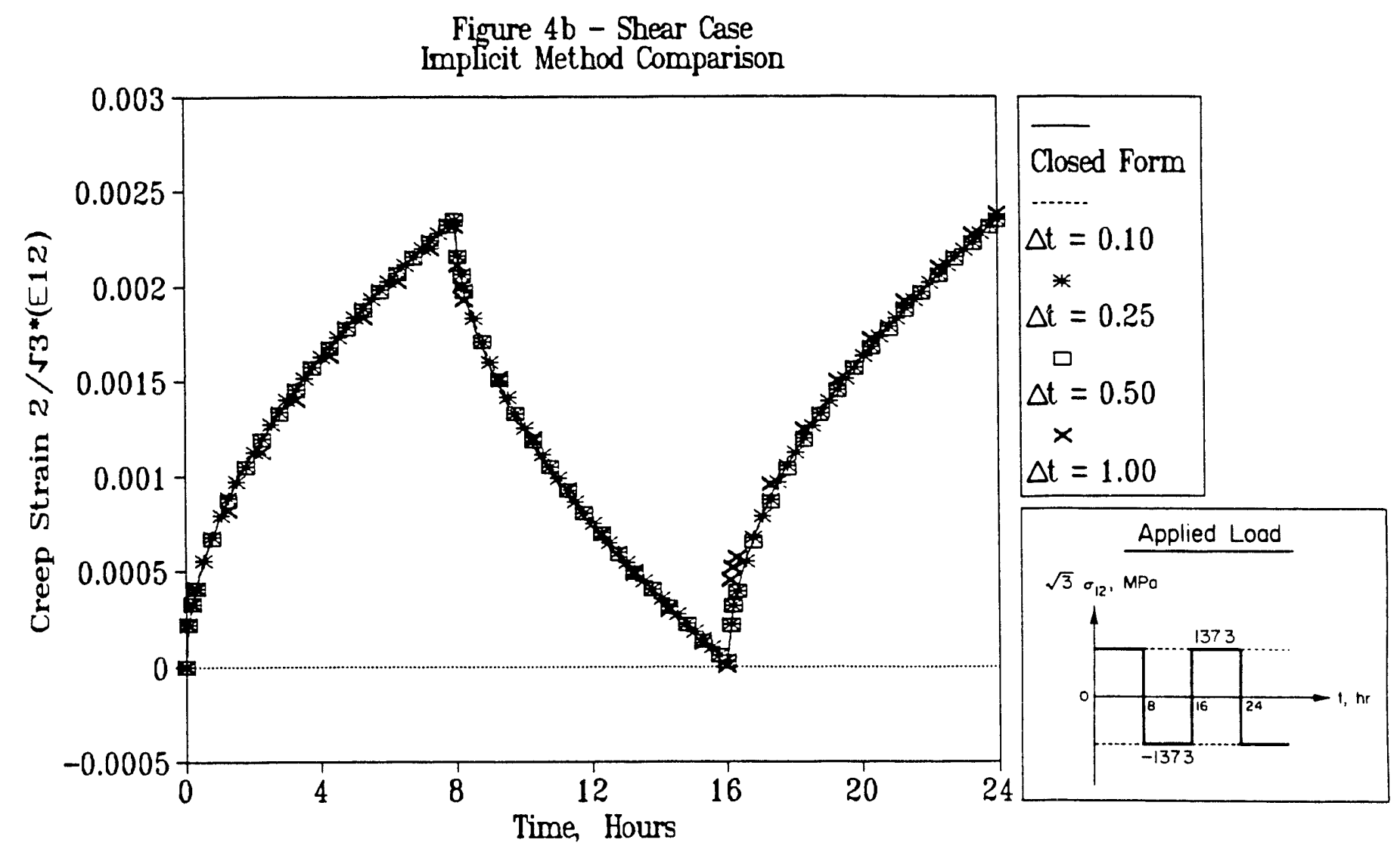

FIGURE 4b. EFFECT OF TIME STEP SIZE $\triangle \mathrm{t}$ ON FE PREDICTION FOR THE PURE SHEAR CASE 
Figure 5 - Pure Shear Case $\theta=180$

Comparison between F.E. \& Experimental

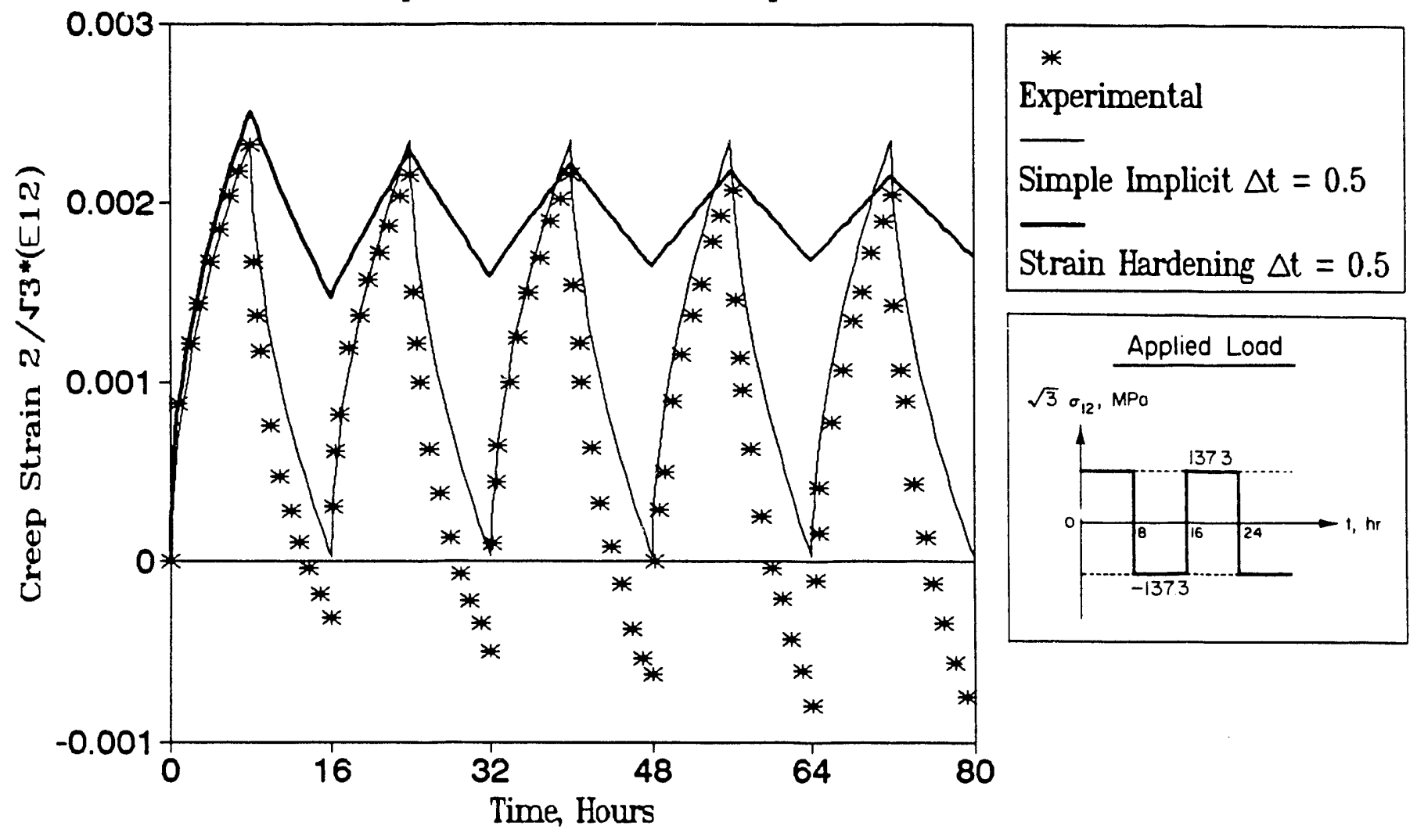

FIGURE 5. COMPARISON BETWEEN FE PREDICTION USING CLASSICAL STRAIN HARDENING AND SIMPLE THEORIES AND EXPERIMENTAL DATA FOR PURE TORSION $\left(\right.$ SHEAR, $\theta=180^{\circ}$ ) 


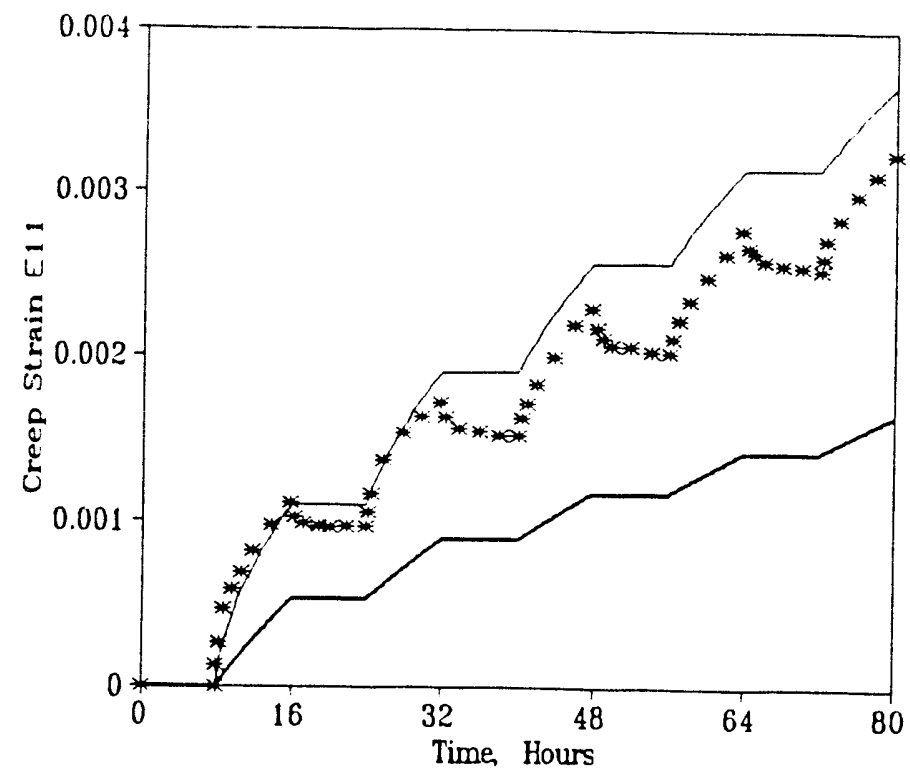

Experimental
Simple-Implicit $\Delta t=0.5$
Strain-Hardening $\Delta t=0.5$

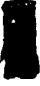

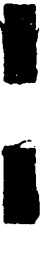

(a)

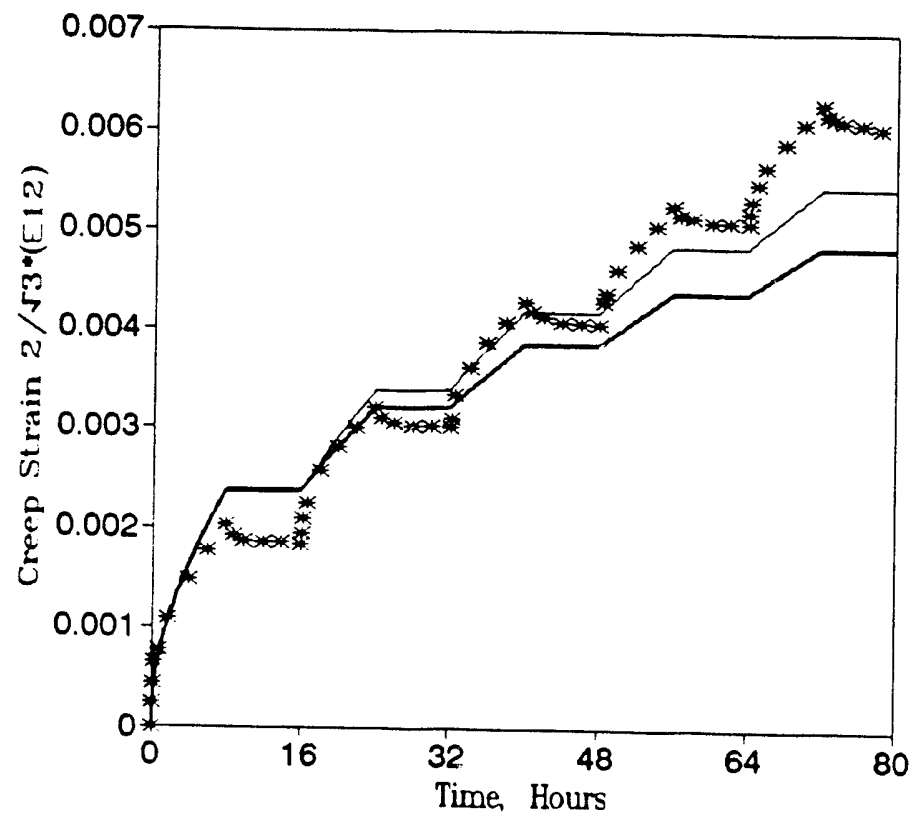

Experimental

Simple-Implicit $\Delta t=0.5$

Strain-Hardening $\Delta t=0.5$

(b)

FIGURE 6. COMPARISON BETWEEN FE PREDICTION AND EXPERIMENTAL RESULTS FOR $\theta=150$ DEGREES (a) STRAIN $E_{11}$ AND

(b) STRAIN $E_{12}$ 


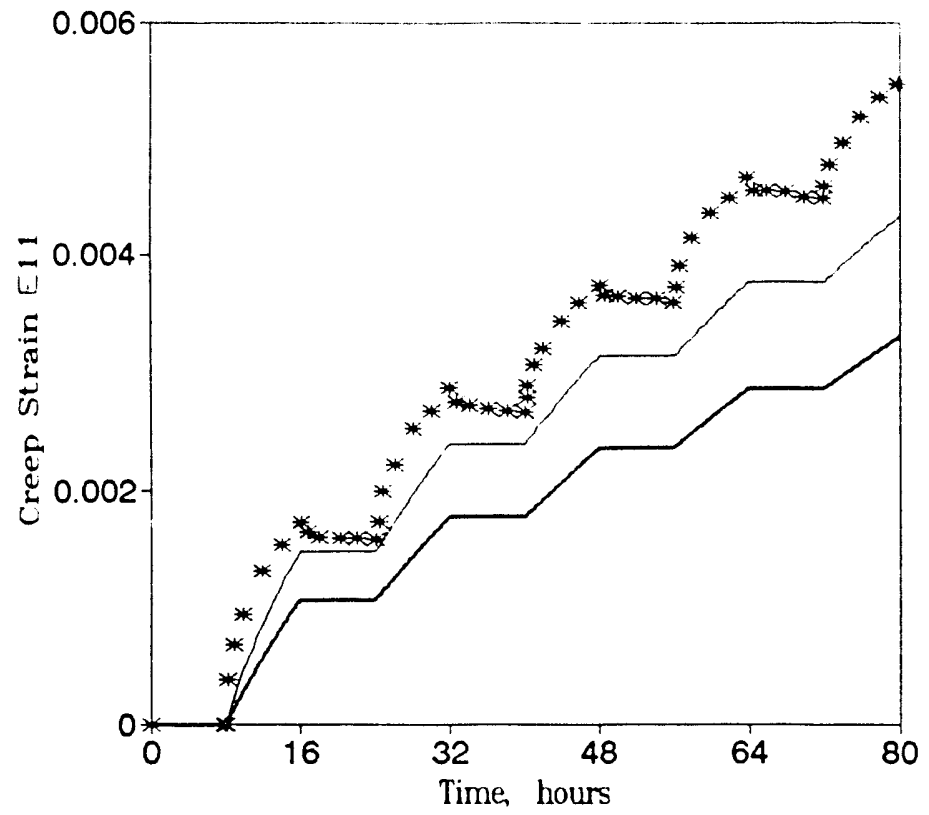

Experimental

Simple-Implicit $\Delta t=0$

Strain-Hardening $\Delta \mathrm{t}=$

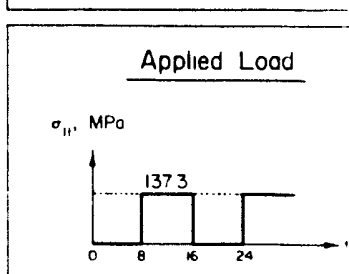

$\sqrt{3} \sigma_{12}, M P O$

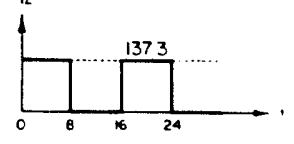

(a)

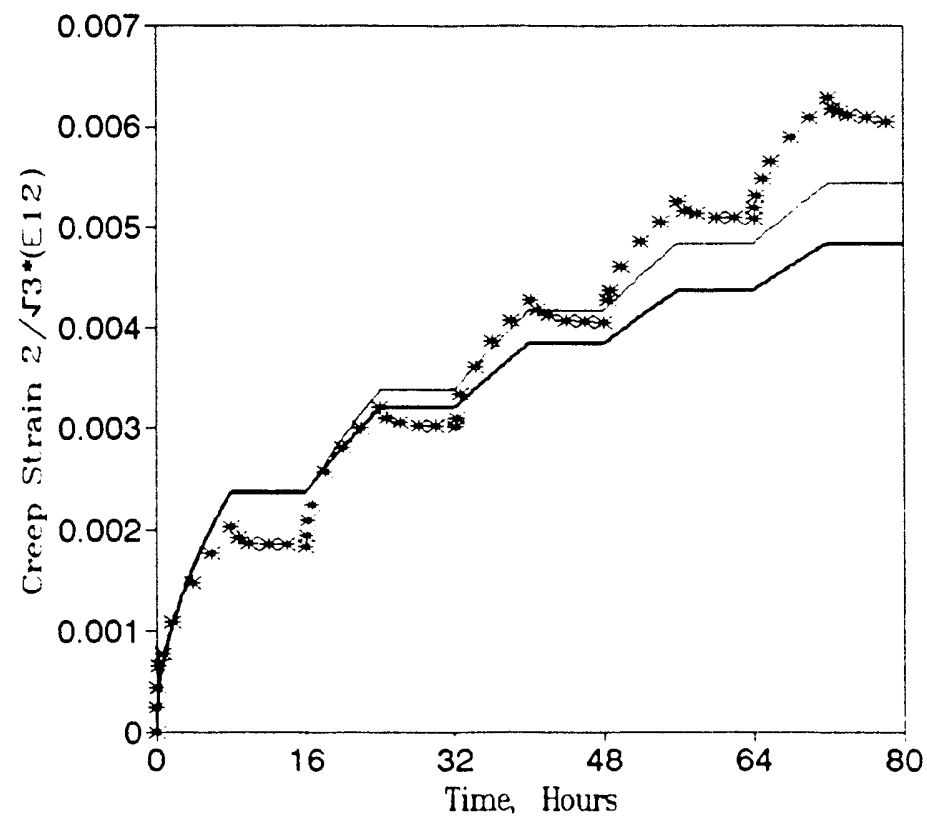

Experimental
Simple-Implicit $\Delta t=0.5$

Strain-Hardening $\Delta t=0$.

Applied Load

$\sigma_{11}, \mathrm{MPo}$

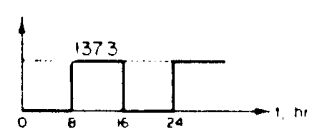

$\sqrt{3} \sigma_{12} \cdot M P_{0}$

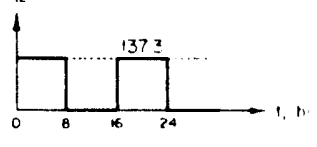

(b)

FIGURE 7. COMPARISON BETWEEN FE PREDICTION AND EXPERIMENTAL RESULTS FOR $\theta=90$ DEGREES (a) STRAIN $E_{11}$ AND

(b) STRAIN E 12 


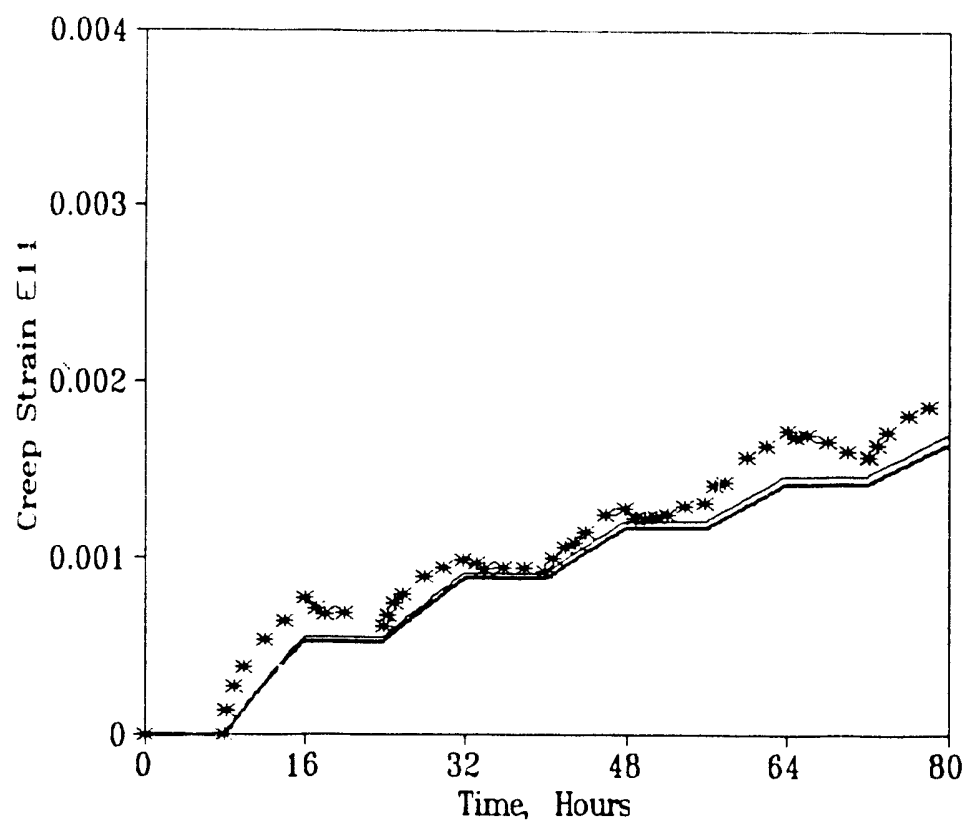

Experimental

Simple-Implicit $\Delta t=$

Strain-Hardening $\Delta t=$

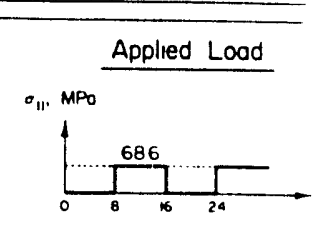

$\sqrt{3} \sigma_{R^{2}}, M P_{0}$

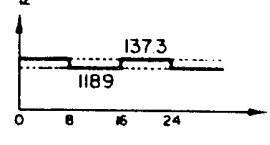

(a)

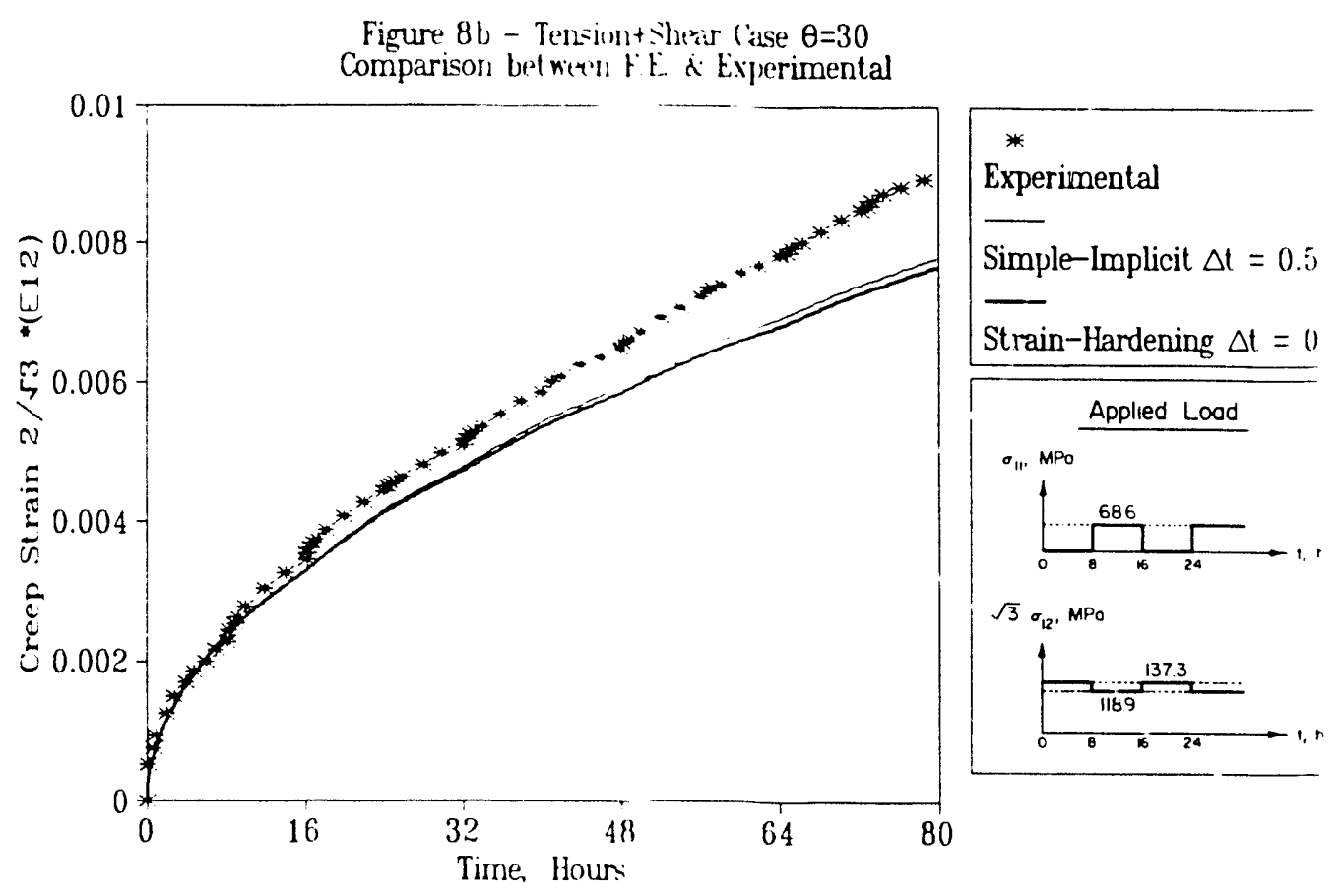

(b)

FIGURE 8. COMPARISON BETWEEN FE PREDICTION AND EXPERIMENTAL RESULTS FOR $\theta=30$ DEGREES (a) STRAIN $E_{11}$ AND

(b) STRAIN E 12 


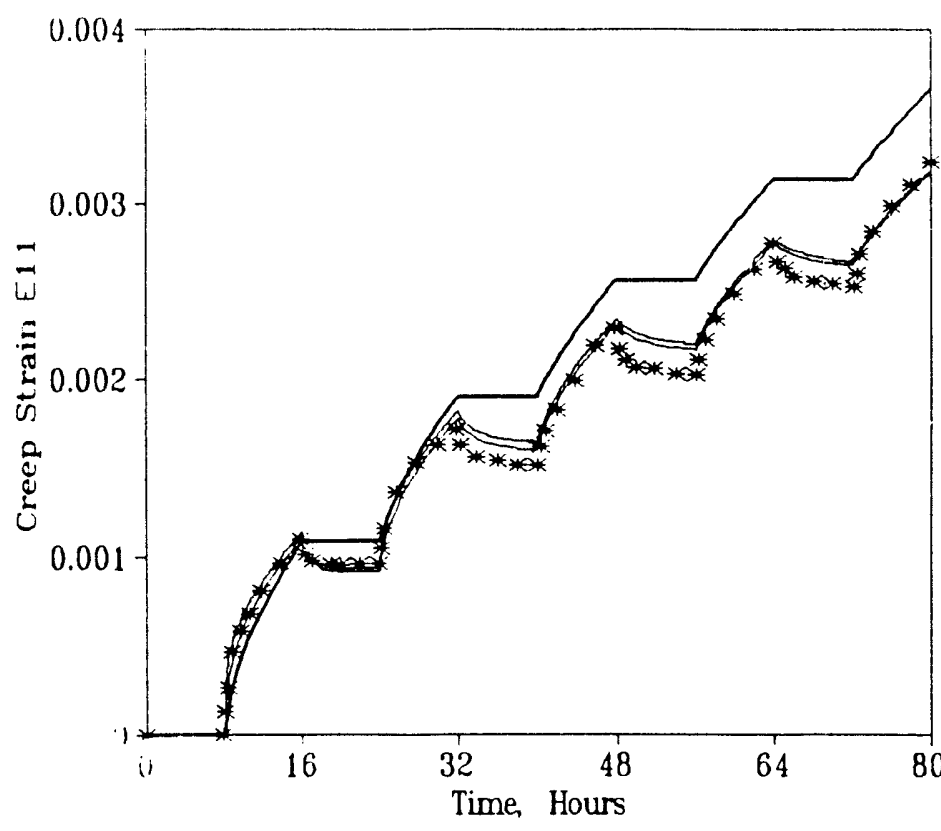

Experimental

Simple-lmplicit $\Delta t=0.5$

Elaborate-Explicit $\Delta t=1$.

Elaborate-Implicit $\Delta \mathrm{t}=1$

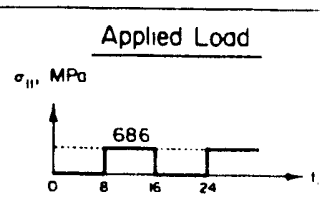

$\sqrt{3} \sigma_{12}, M P O$

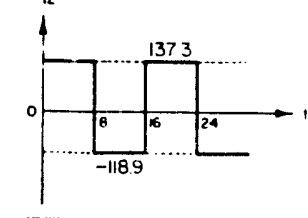

(a)

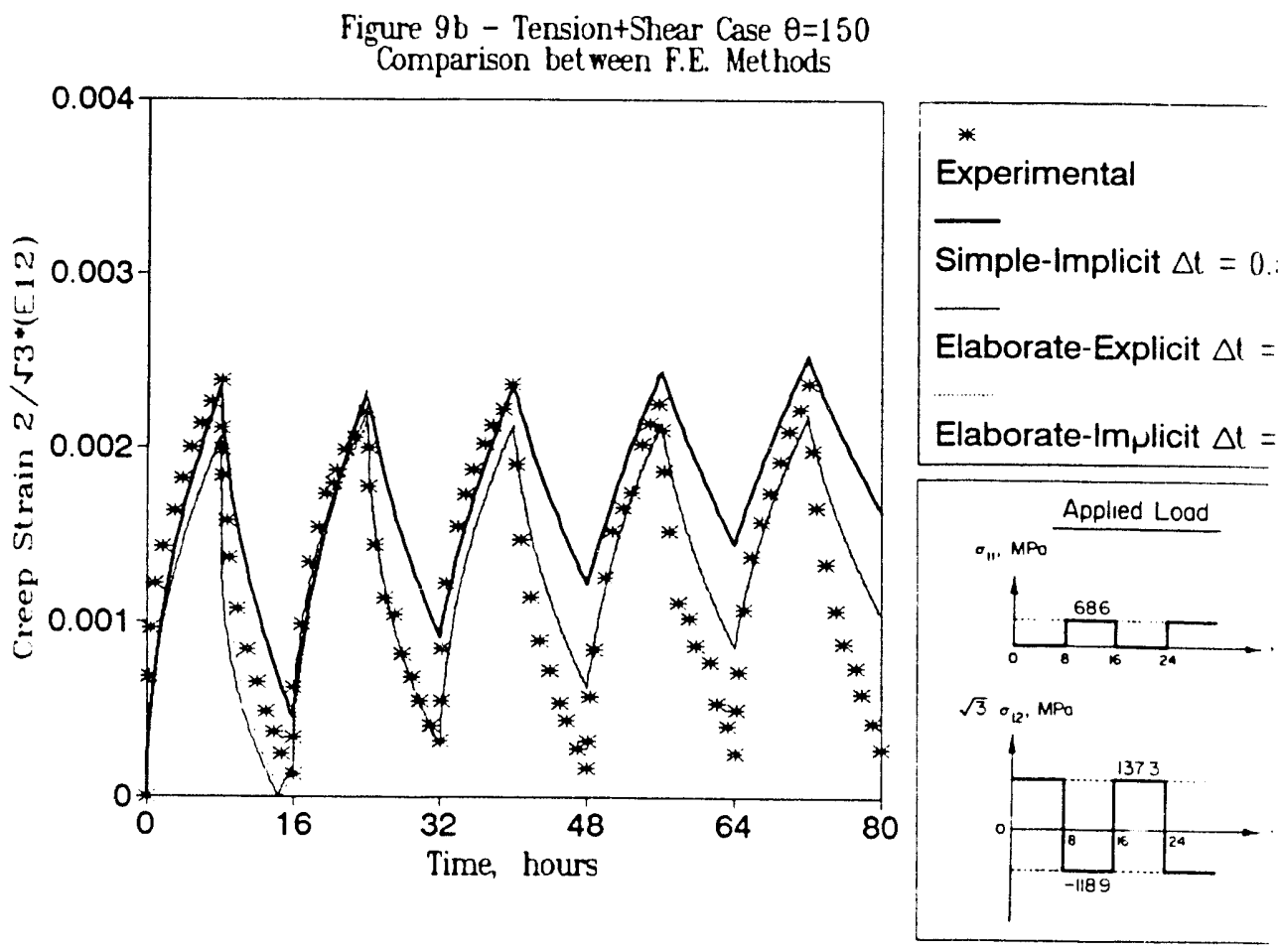

(b)

FIGURE 9. COMPARISON BETWEEN FE PREDICTION AND EXPERIMENTS FOR $\theta=150$ DEGREES USING THE ELABORATE AS WELL AS SIMPLE THEORIES (a) STRAIN E ${ }_{11}$ AND (b) STRAIN E ST $_{12}$ 


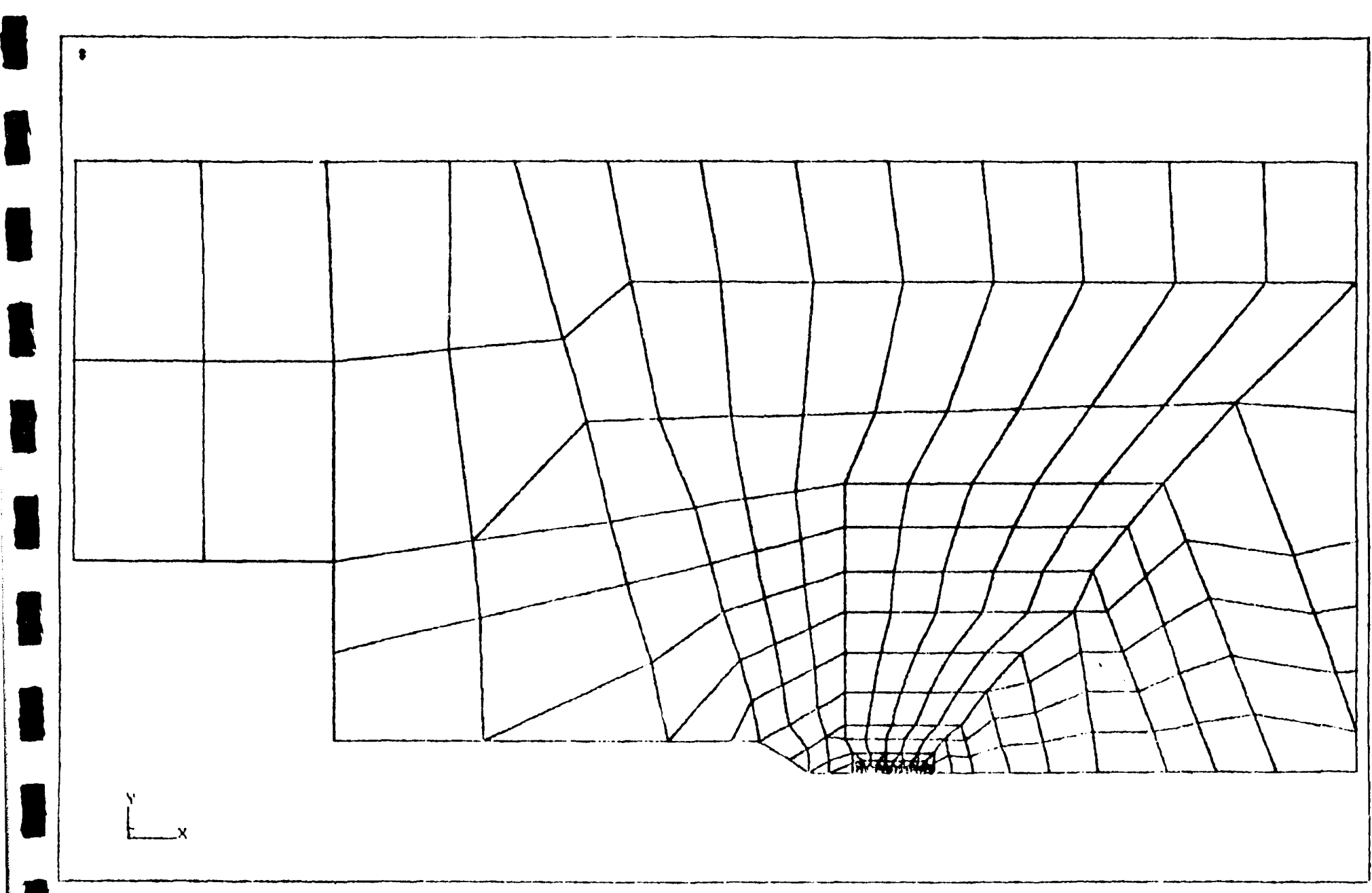

(a)

FIGURE 10. TYPICAL FINITE ELEMENT MESH USED FOR ANALYSES. NOTE THE LINE MESH IN THE DIRECTION OF CRACK GROWTH. 


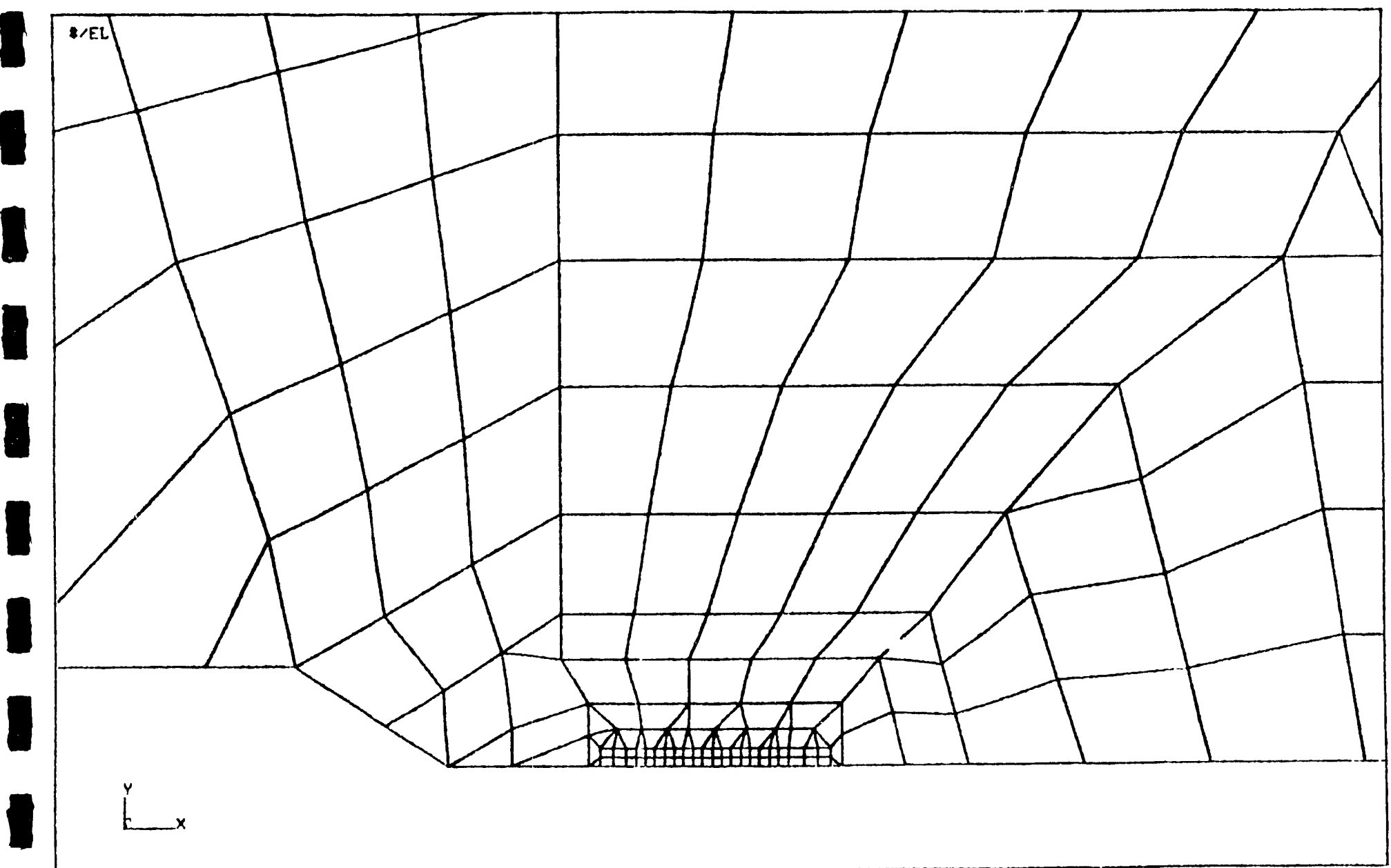

(b)

FIGURE 10. TYPICAL FINITE ELEMENT MESH USED FOR ANALYSES. NOTE THE LINE MESH IN THE DIRECTION OF CRACK GROWTH. 


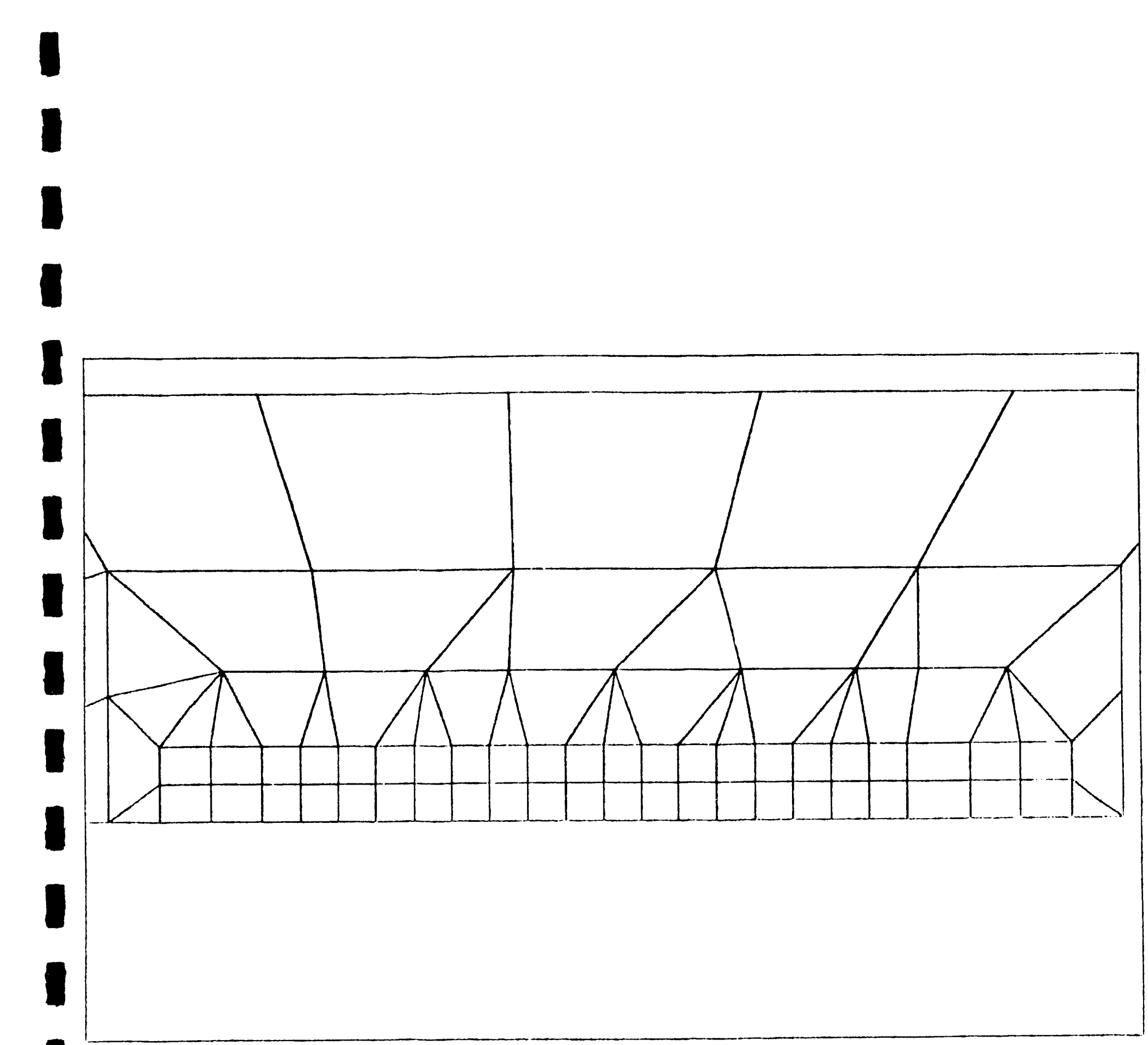

(c)

FIGURE 10. TYPICAL FINITE ELEMENT MESH USED FOR ANALYSES. NOTE THE LINE MESH IN THE DIRECTIOIN OF CRACK GROWTH. 


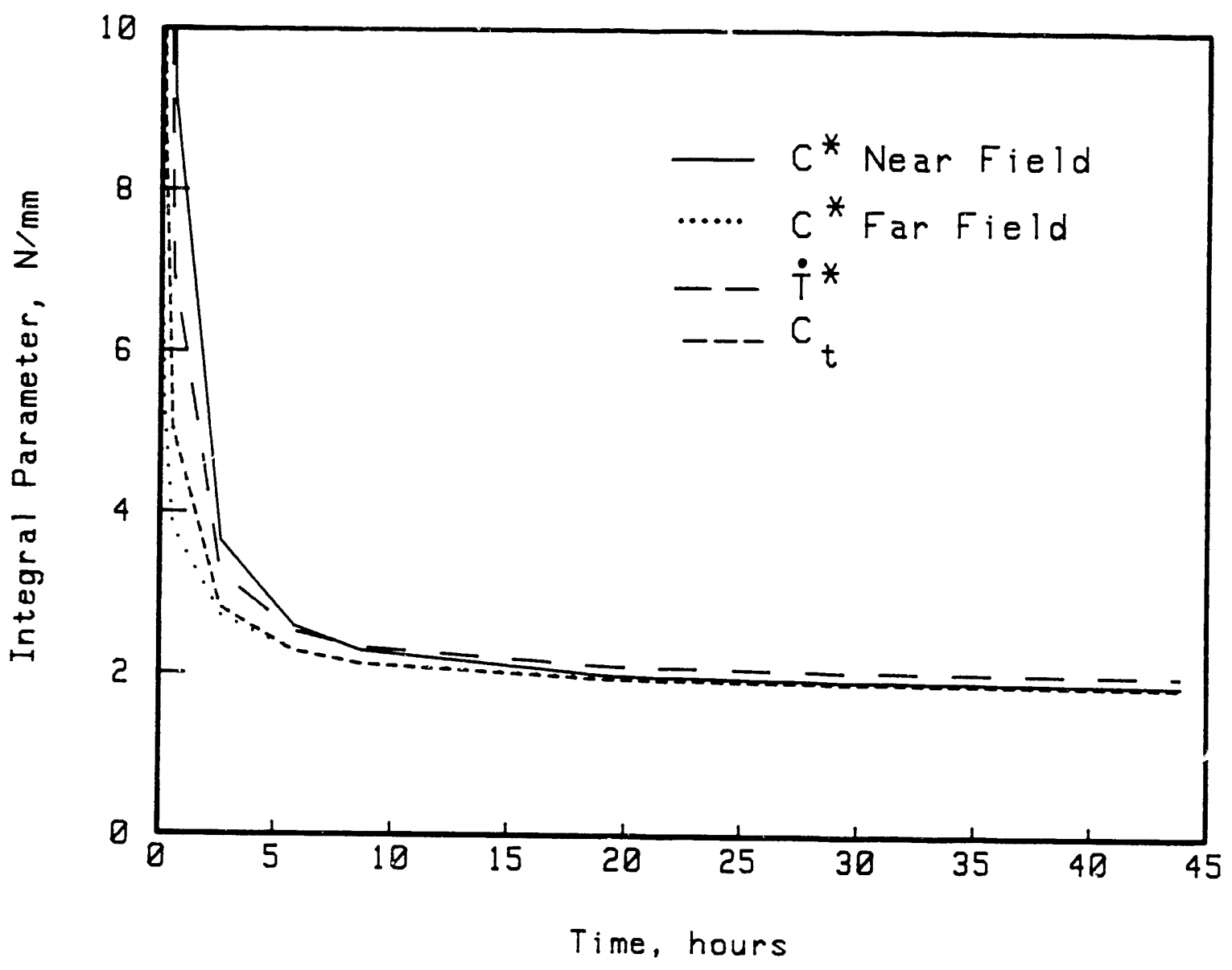

FIGURE 11. BEHAVIOR OF $\mathbf{C}^{*}, \mathrm{C}_{\mathfrak{r}}$ AND $\dot{\mathrm{T}}^{*}$ FOR A CREEPING STATIONARY CRACK 


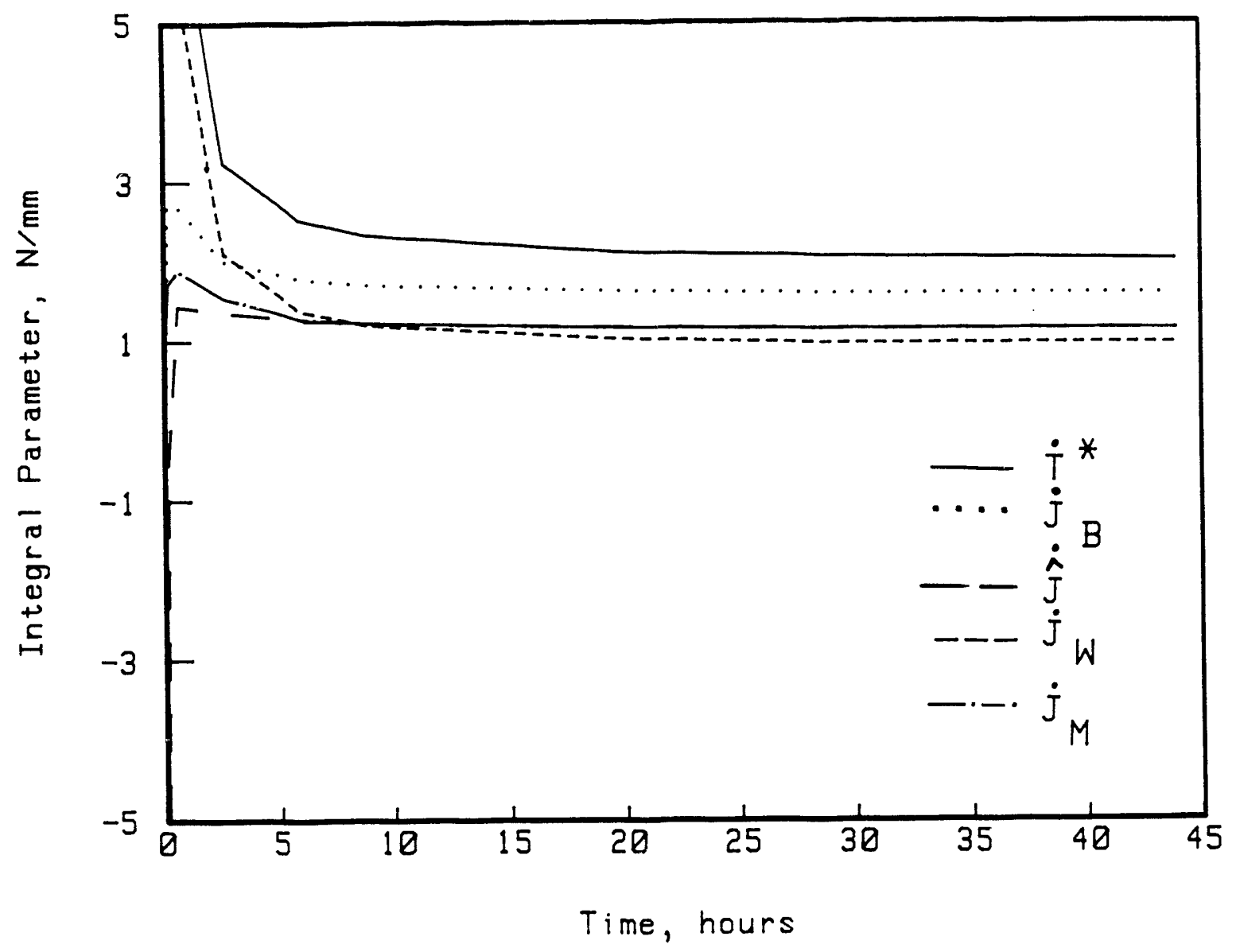

FIGURE 12. BEHAVIOR OF VARIOUS INTEGRAL RATE PARAMETERS AS A FUNCTION OF TIME FOR A STATIONARY CRACK 


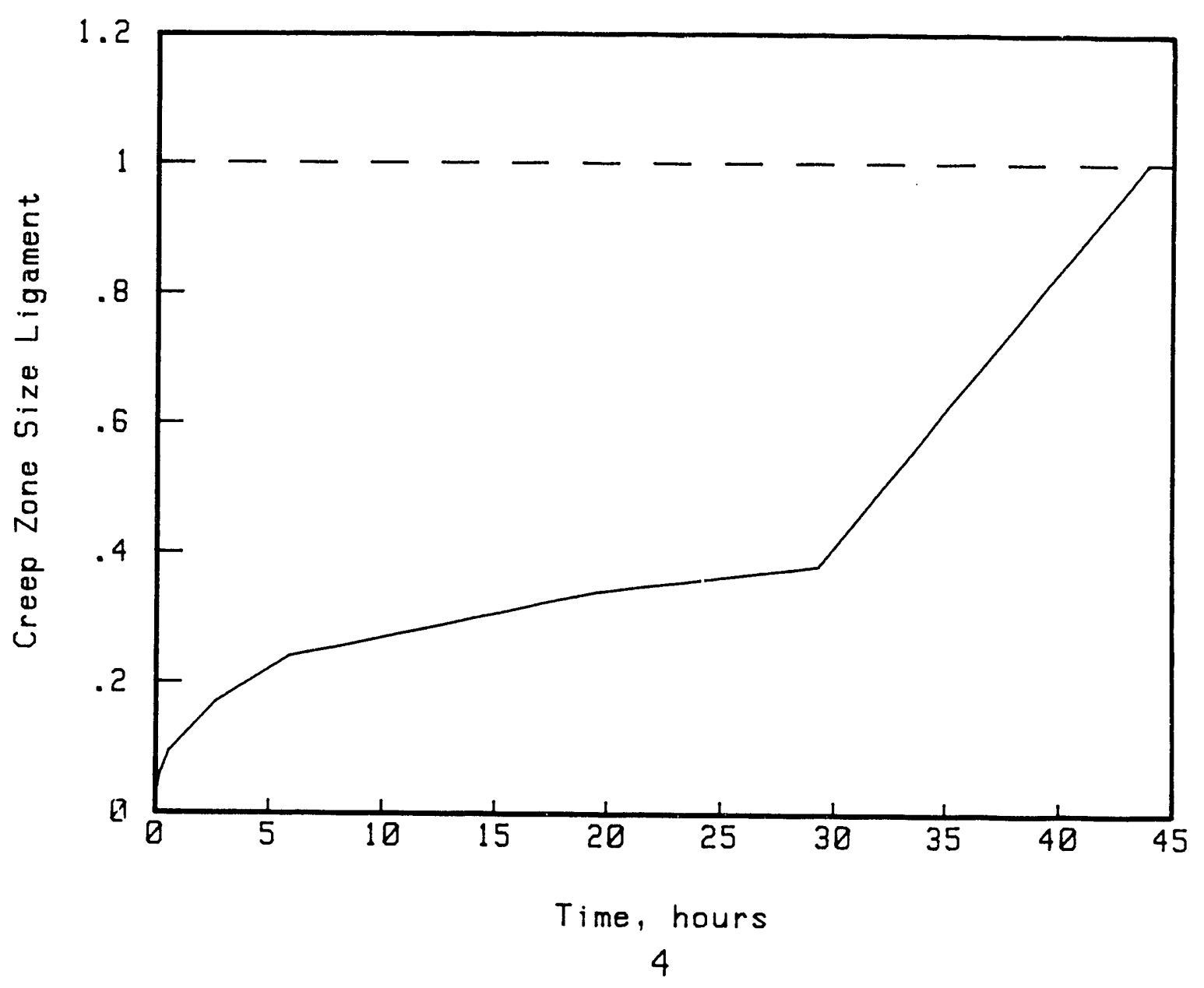

FIGURE 13. DEVELOPMENT OF CREEP ZONE SIZE LIGAMENT FOR STATIONARY CRACK 


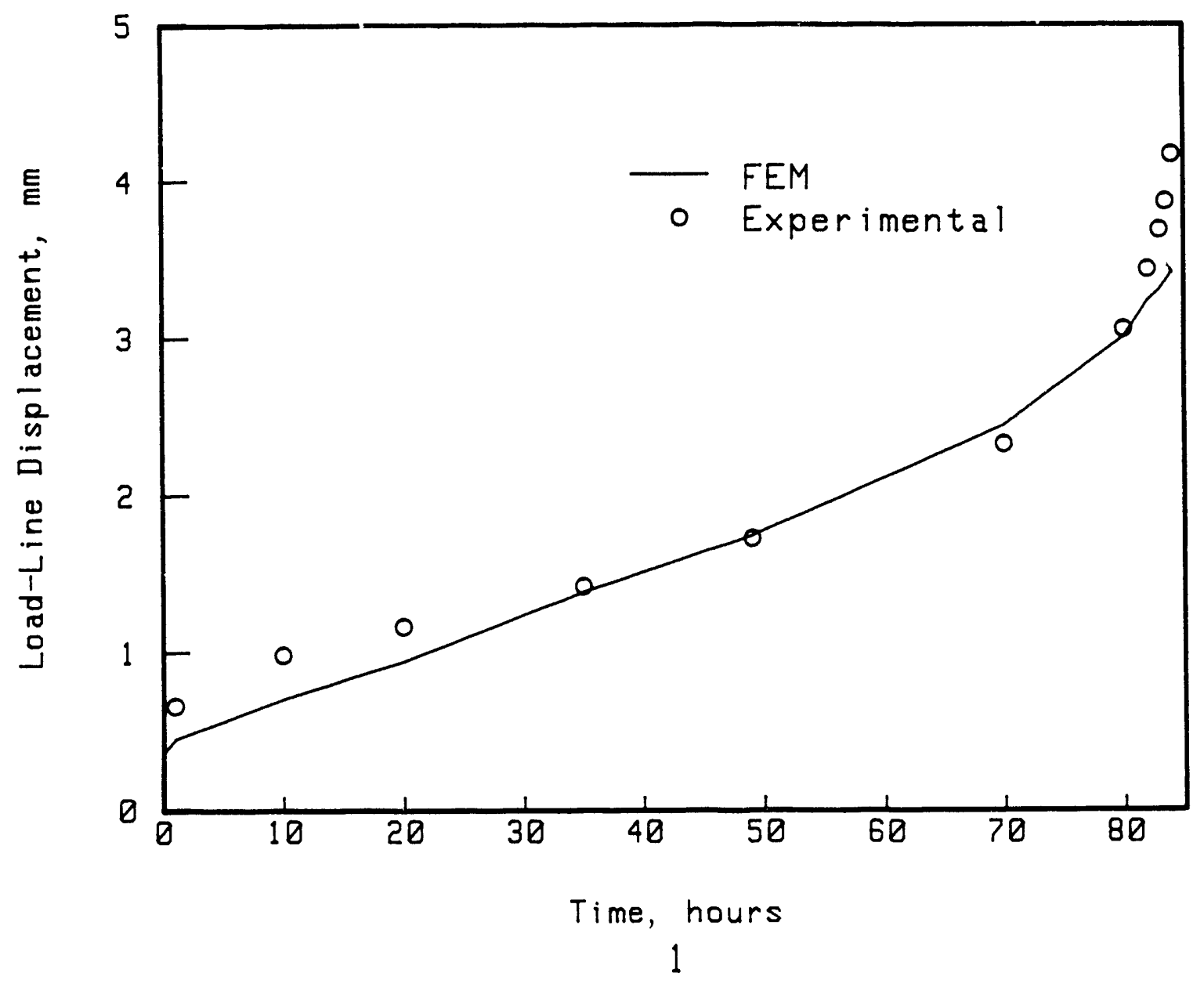

FIGURE 14. COMPARISON OF EXPERIMENTAL AND PREDICTED DISPLACEMENTS FOR A COMPACT TENSION SPECIMEN LOAD AND HELD AT LOAD TO FAILURE AT 84 HOURS 


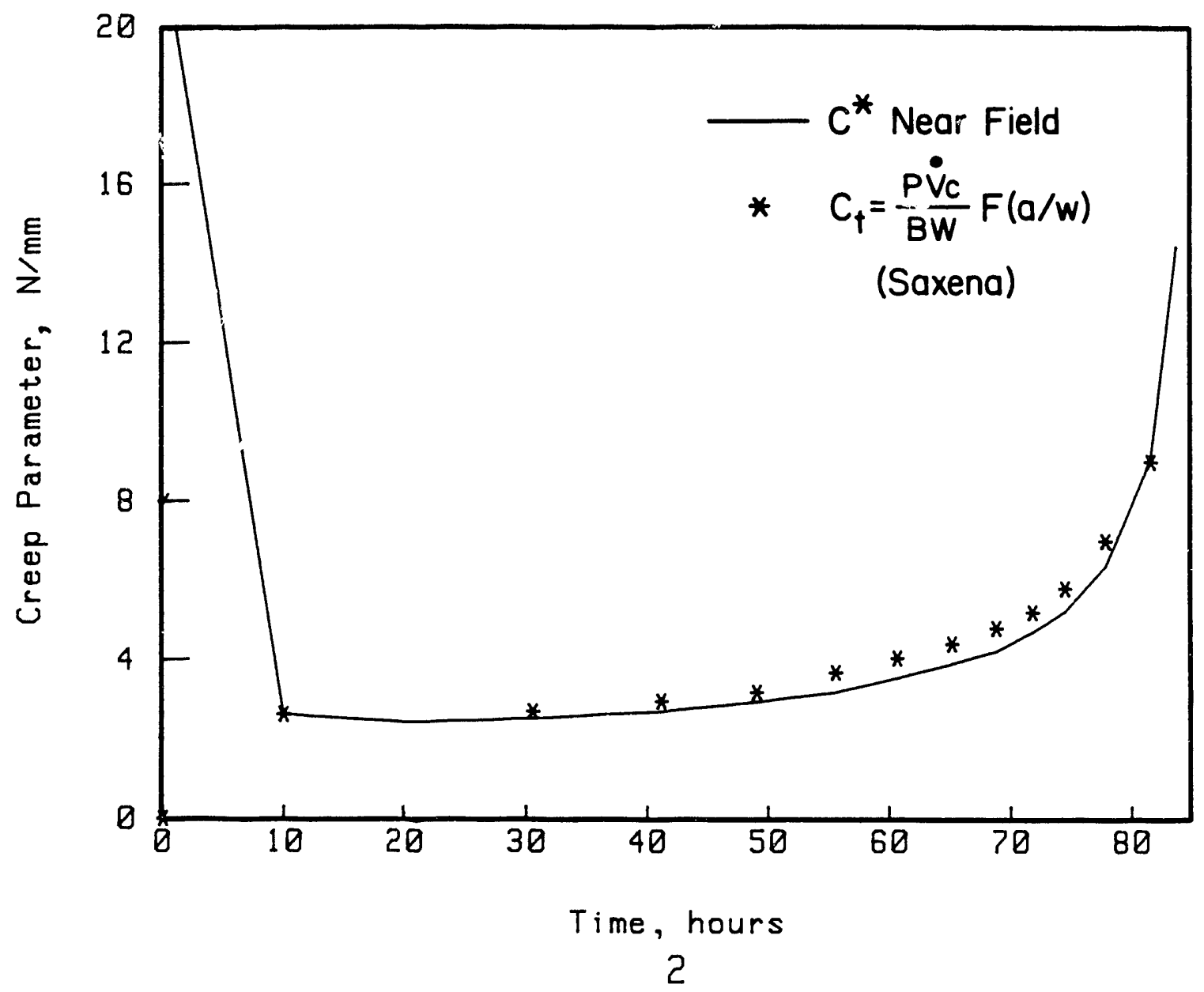

FIGURE 15. COMPARISON OF $C^{\circ}$ EVALUATED ALONG A NEAR FIELD PATH AND THE FAR FIELD C" PARAMETER 
I

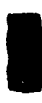

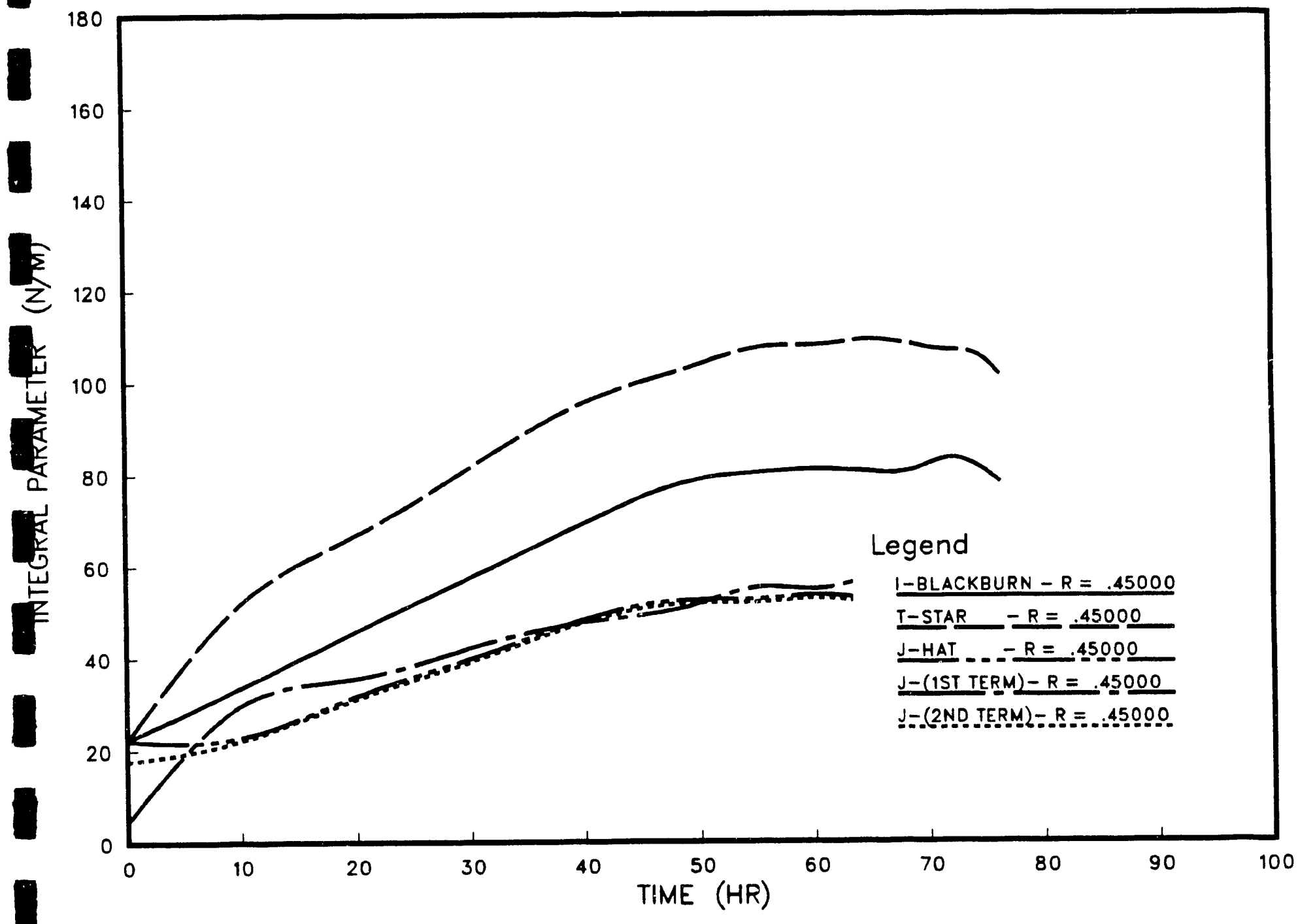

INTEGRAL PARAMETER VS. TIME

FIGURE 16. INTEGRAL PARAMETERS VERSUS TIME FOR $\mathrm{R}=.45 \mathrm{MM}$ 


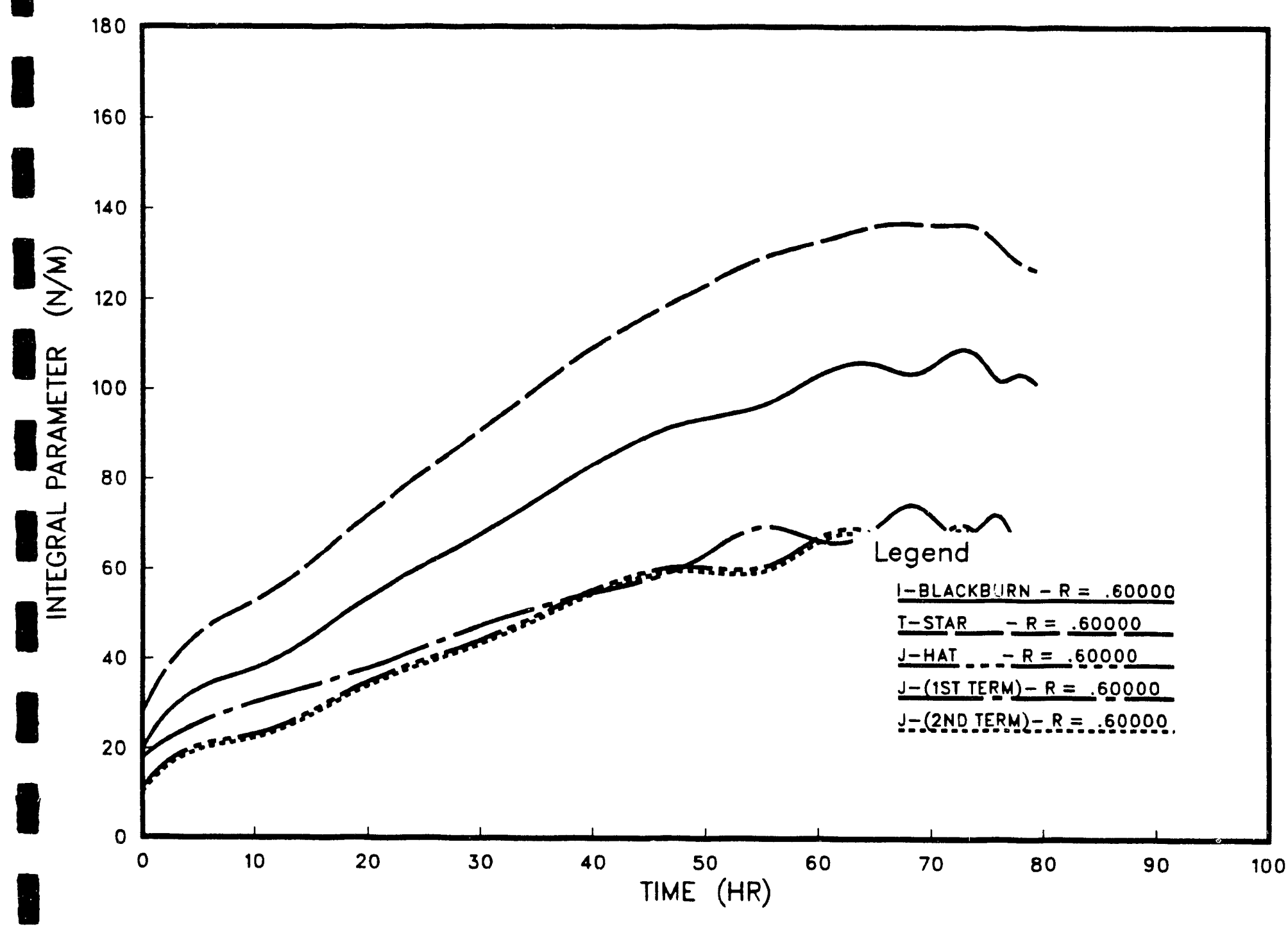

INTEGRAL PARAMETER VS. TIME

FIGURE 17. INTEGRAL PARAMETERS VERSUS TIME FOR $R=.60 \mathrm{M}$ 


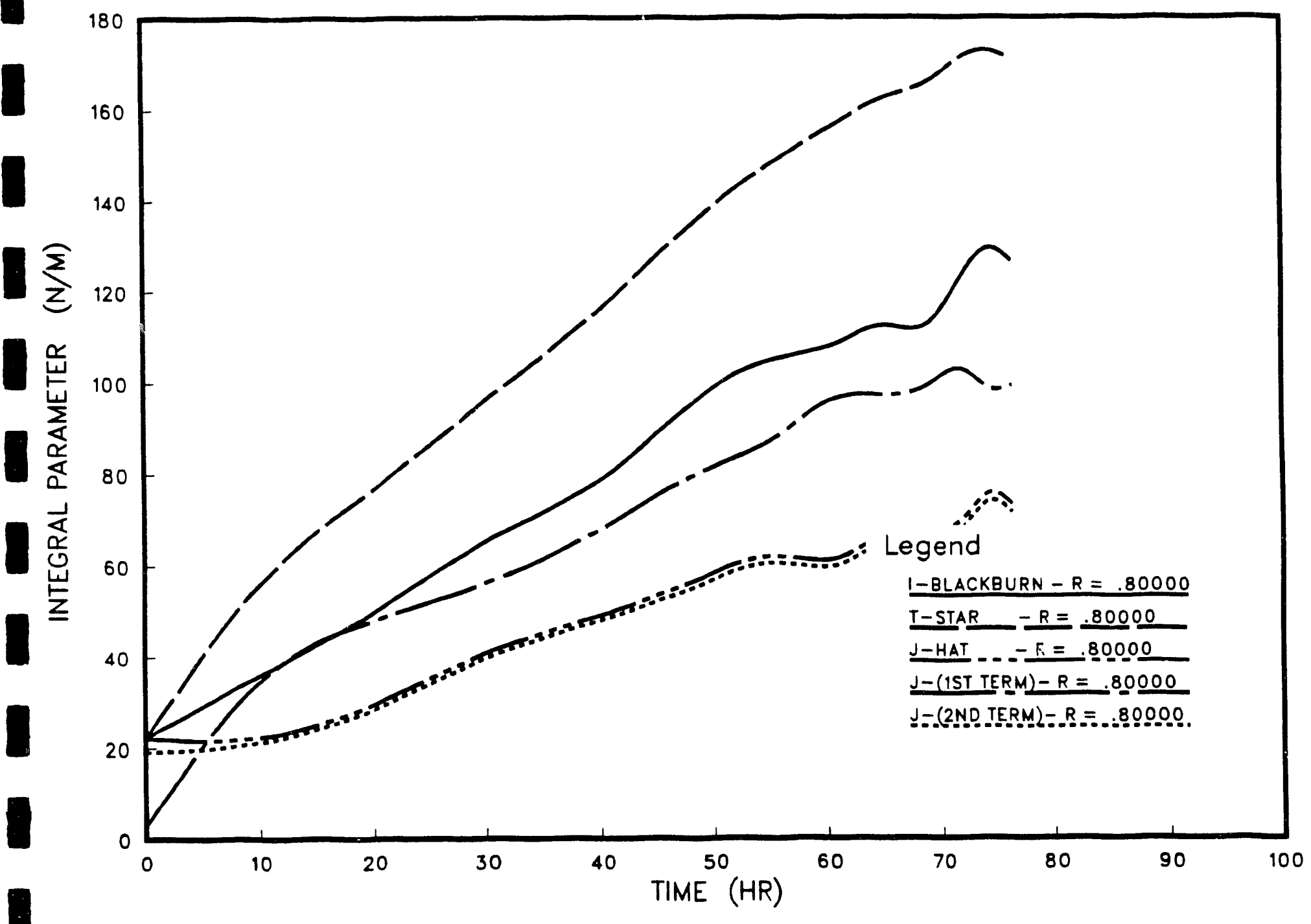

INTEGRAL PARAMETER VS. TIME

FIGURE 18. INTEGRAL PARAMETERS VERSUS TIME FOR $\mathrm{R}=.80 \mathrm{M}$ 


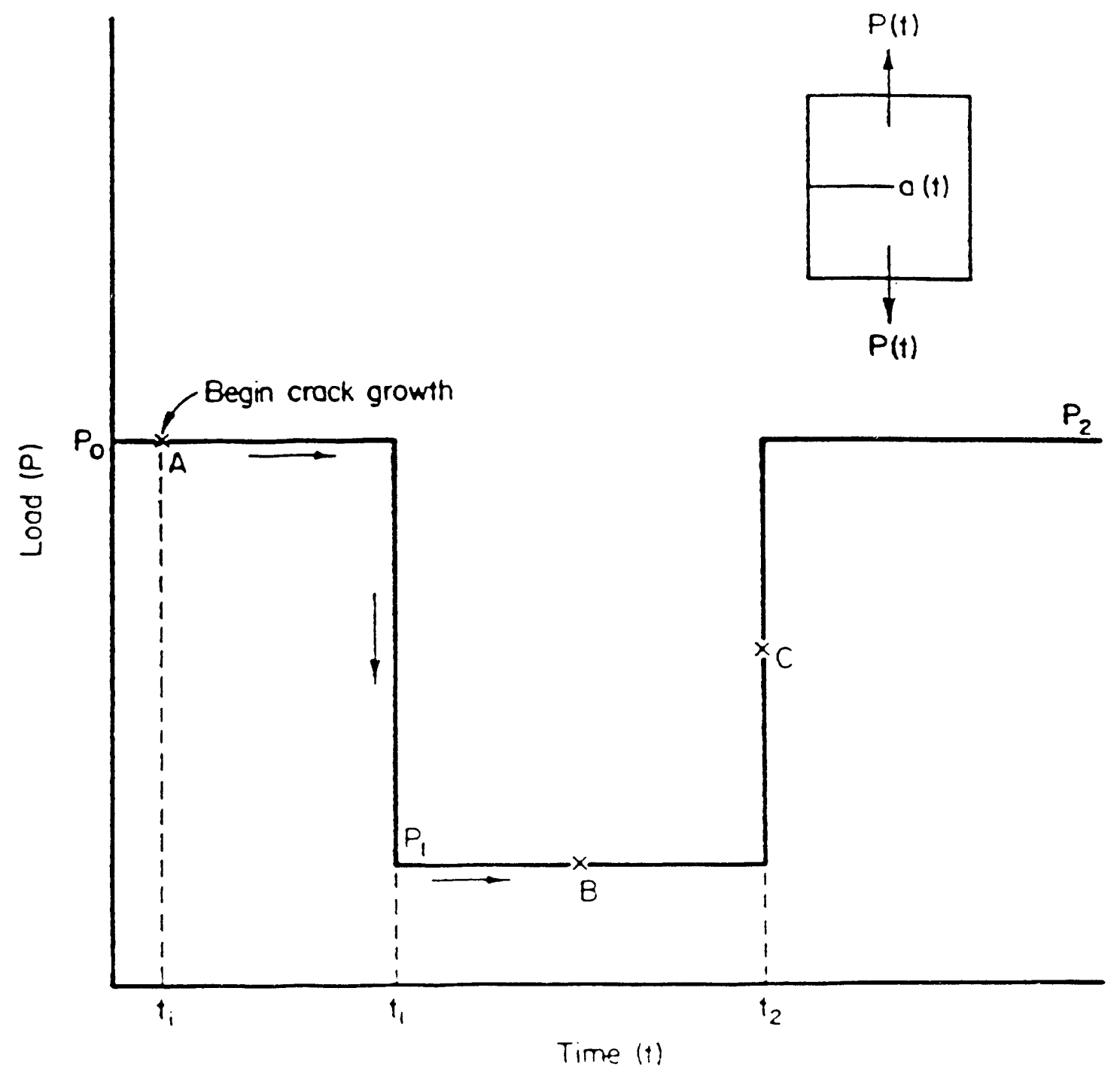

FIGURE 19. POSSIBLE LOAD-VERSUS-TIME HISTORY OF A SOLID OPERATING AT HIGH TEMIFER ATURES 


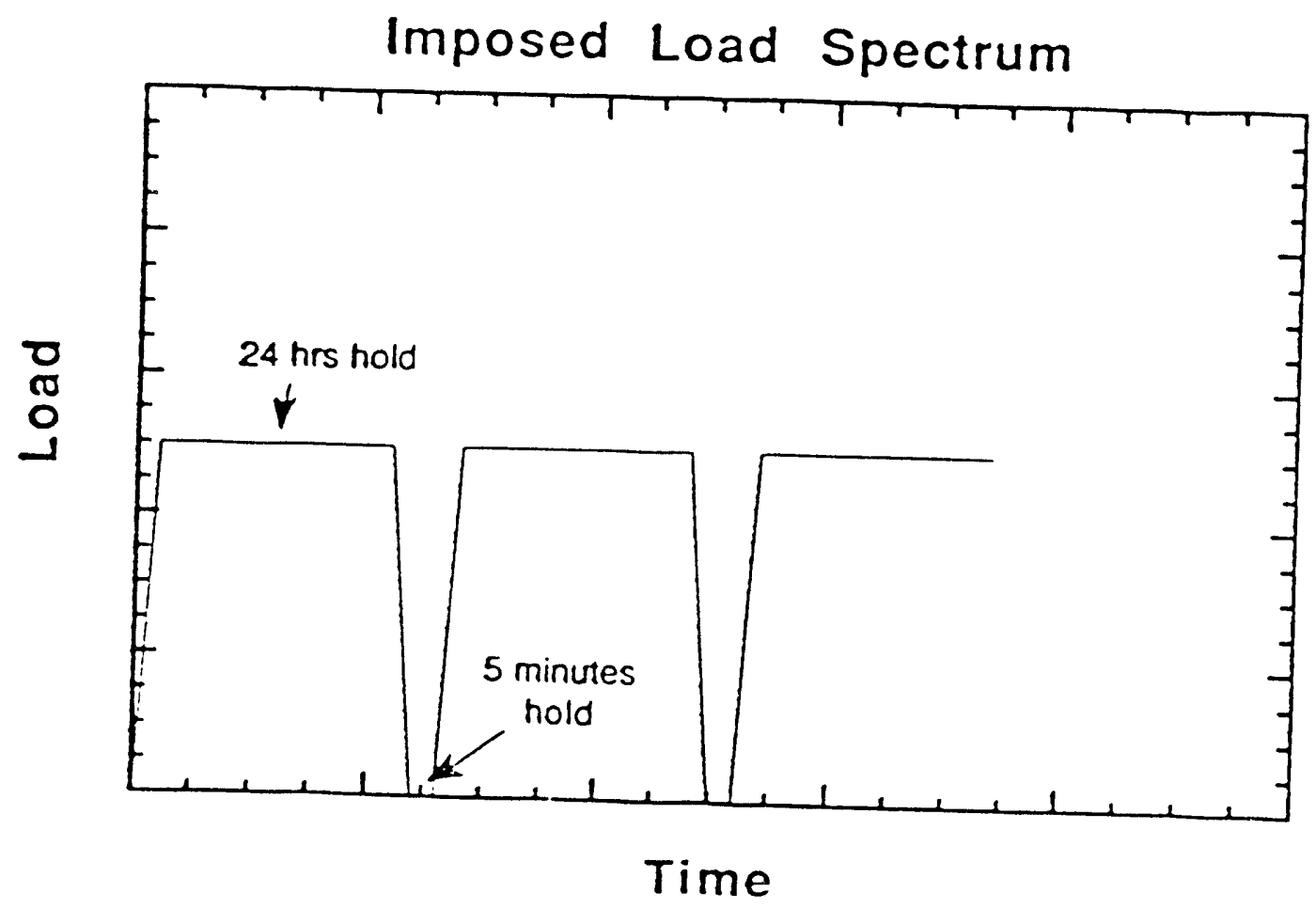

FIGURE 20. LOAD SPECTRUM FOR A 9CR-1MO-V-NB COMPACT SPECIMEN LOADED AT $538 \mathrm{C}$ 
RAW DATA

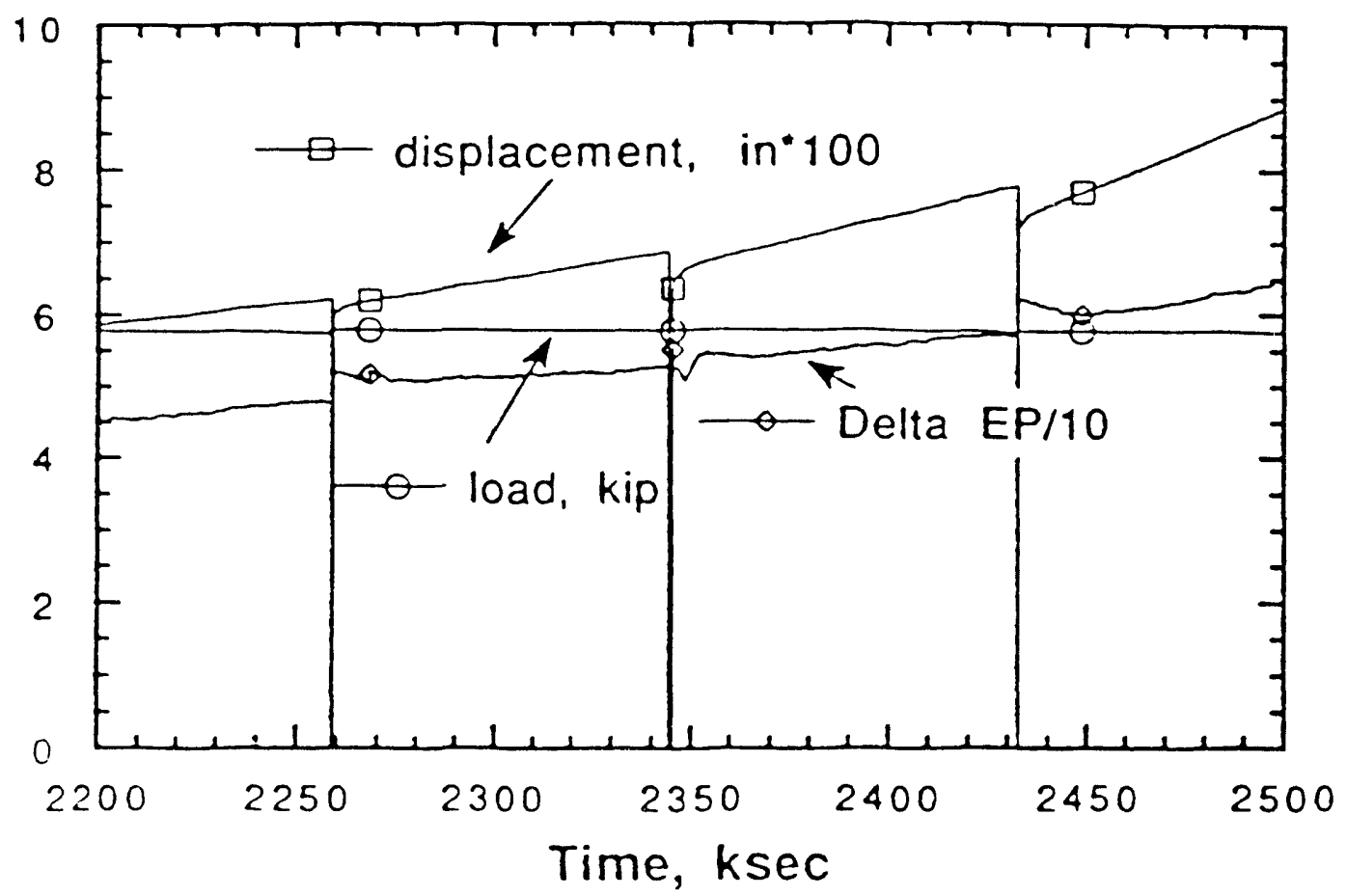

FIGURE 21. LOAD, LOAD-POINT DISPLACEMENT, AND ELECTRIC POTENTIAL (EP) DATA FOR A 9CR-1MO-V-NB COMPACT TENSION SPECIMEN, SUBJECTED TO THE LOAD SPECTRUM SHOWN IN FIGURE 20 

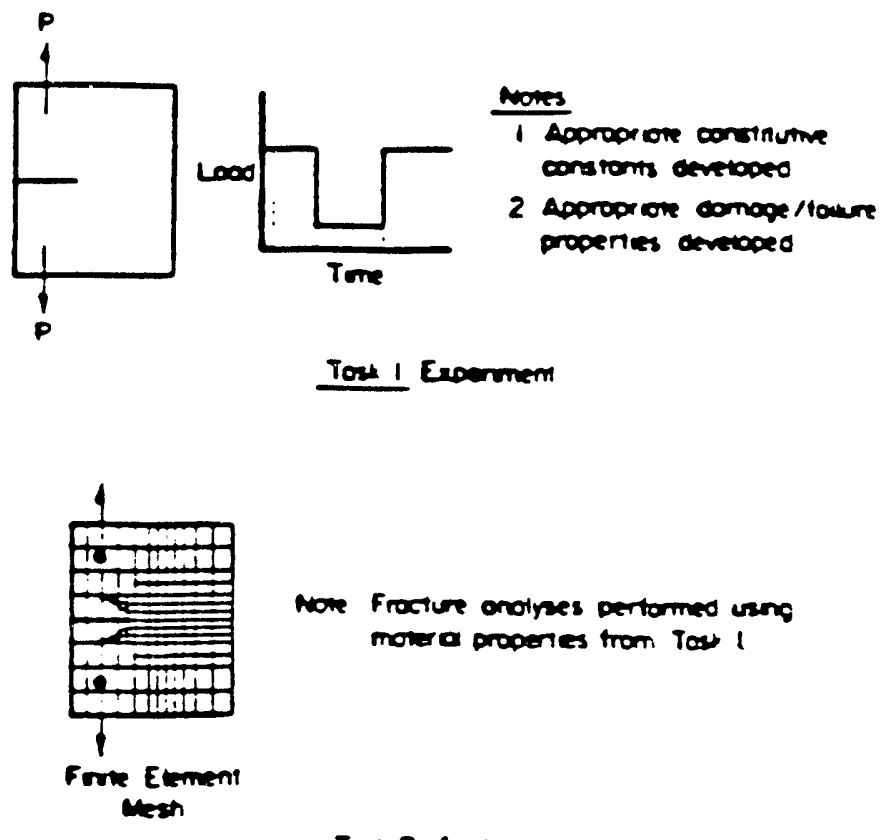

Tor 2 Anomes

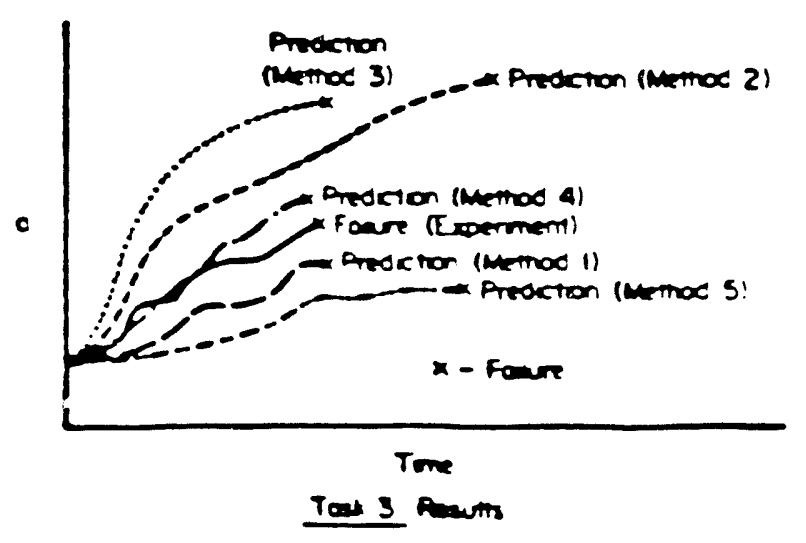

FIGURE 22. SCHEMATIC OF RESEARCH APPROACH 

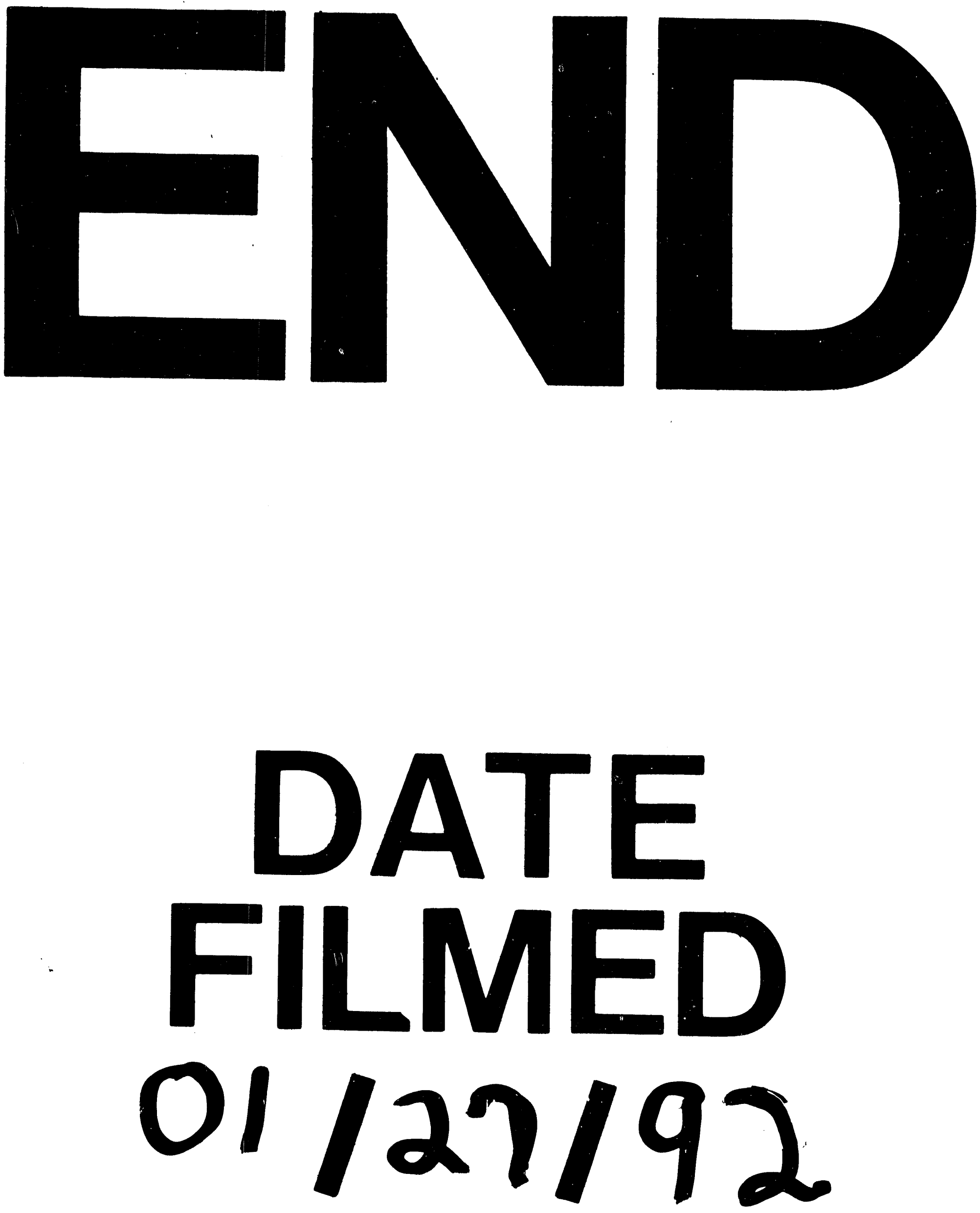
